\title{
Nucleation and growth of sulfate aerosol in coal-fired power plant plumes: sensitivity to background aerosol and meteorology
}

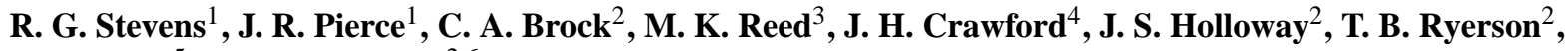 \\ L. G. Huey ${ }^{5}$, and J. B. Nowak ${ }^{2,6}$ \\ ${ }^{1}$ Department of Physics and Atmospheric Science, Dalhousie University, Halifax, NS, Canada \\ ${ }^{2}$ NOAA Earth System Research Laboratory, Boulder, CO, USA \\ ${ }^{3}$ Tennessee Technological University, Cookeville, TN, USA \\ ${ }^{4}$ NASA Langley Research Center, Hampton, VA, USA \\ ${ }^{5}$ Department of Earth and Atmospheric Science, Georgia Institute of Technology, Atlanta, GA, USA \\ ${ }^{6}$ Cooperative Institute for Research in Environmental Sciences, University of Colorado, Boulder, CO, USA
}

Correspondence to: R. G. Stevens (robin.stevens@dal.ca)

Received: 10 August 2011 - Published in Atmos. Chem. Phys. Discuss.: 5 September 2011

Revised: 12 December 2011 - Accepted: 13 December 2011 - Published: 3 January 2012

\begin{abstract}
New-particle formation in the plumes of coalfired power plants and other anthropogenic sulfur sources may be an important source of particles in the atmosphere. It remains unclear, however, how best to reproduce this formation in global and regional aerosol models with grid-box lengths that are 10s of kilometers and larger. The predictive power of these models is thus limited by the resultant uncertainties in aerosol size distributions. In this paper, we focus on sub-grid sulfate aerosol processes within coal-fired power plant plumes: the sub-grid oxidation of $\mathrm{SO}_{2}$ with condensation of $\mathrm{H}_{2} \mathrm{SO}_{4}$ onto newly-formed and pre-existing particles. We have developed a modeling framework with aerosol microphysics in the System for Atmospheric Modelling (SAM), a Large-Eddy Simulation/Cloud-Resolving Model (LES/CRM). The model is evaluated against aircraft observations of new-particle formation in two different power-plant plumes and reproduces the major features of the observations. We show how the downwind plume aerosols can be greatly modified by both meteorological and background aerosol conditions. In general, new-particle formation and growth is greatly reduced during polluted conditions due to the large pre-existing aerosol surface area for $\mathrm{H}_{2} \mathrm{SO}_{4}$ condensation and particle coagulation. The new-particle formation and growth rates are also a strong function of the amount of sunlight and $\mathrm{NO}_{\mathrm{x}}$ since both control $\mathrm{OH}$ concentrations. The results of this study highlight the importance
\end{abstract}

for improved sub-grid particle formation schemes in regional and global aerosol models.

\section{Introduction}

It has been established that aerosols have a cooling effect on climate through the direct and indirect aerosol effects, but the magnitude of these effects is still very uncertain (Solomon et al., 2007). It has also been demonstrated that both the direct (Charlson et al., 1992) and indirect (Twomey, 1974; Albrecht, 1989) effects strongly depend on the size of the particles involved. The size distribution of particles also determines, in part, the effects on human health of the particles. Particles are known to have adverse effects on respiratory health in humans (Dockery et al., 1993), and ultrafine particles (with diameters less than $0.1 \mu \mathrm{m}$ in diameter) may have stronger effects than larger particles (Peters et al., 1997).

Coal-fired power plants are major emitters of sulfur dioxide " $\mathrm{SO}_{2}$ " (Whitby, 1978; Hegg and Hobbs, 1980; Hegg et al., 1985). Concentrations of $\mathrm{SO}_{2}$ in the plumes of these power plants are generally much higher than in a typical planetary boundary layer. When $\mathrm{SO}_{2}$ is oxidized by the hydroxyl radical $(\mathrm{OH})$ in the gas phase, it forms sulfuric acid $\left(\mathrm{H}_{2} \mathrm{SO}_{4}\right)$, a low-volatility vapor. $\mathrm{H}_{2} \mathrm{SO}_{4}$ will condense onto pre-existing particles, and if its concentration is high

Published by Copernicus Publications on behalf of the European Geosciences Union. 
enough, it will cluster with itself and other condensible gases to form new particles (i.e. aerosol nucleation; Kulmala and Kerminen, 2008). Through new-particle formation in their plumes, coal-fired power plants and other anthropogenic sulfur sources can have a significant effect on particle concentrations globally, particularly in the Northern Hemisphere (Adams and Seinfeld, 2003; Luo and Yu, 2011; Spracklen et al., 2005; Wang and Penner, 2009).

Unfortunately, the plume-scale chemistry and physics that lead to particle formation are difficult to represent in regional and global aerosol models. Concentrations of gases, aerosols and relevant variables for particle formation such as temperature and relative humidity are not homogeneous within these plumes, let alone across the spatial scales of a typical global chemical-transport model grid-box. $\mathrm{H}_{2} \mathrm{SO}_{4}$ vapor concentrations that drive new-particle formation within a given plume may be sensitive to $\mathrm{NO}_{\mathrm{x}}$ (nitric oxide (NO) + nitrogen dioxide $\left.\left(\mathrm{NO}_{2}\right)\right)$ concentrations, $\mathrm{OH}$ concentrations, and the condensation sink (approximately proportional to aerosol surface area), which are also not homogeneous within a given plume. Thus, nucleation and growth rates, which are a strong function of $\mathrm{H}_{2} \mathrm{SO}_{4}$ concentrations, will be location dependent in plumes. Coagulation rates of newly formed particles will also vary with location in the plume. For all of these reasons, current global and regional models cannot accurately resolve particle formation and growth in power-plant plumes using values averaged over the volume of a model grid box.

Regional and global models with online aerosol chemistry and physics have therefore made crude assumptions about the sub-grid processes within power-plant plumes that do not depend on the nature of the source or the ambient conditions. These assumptions result in two common simplifications. The first common simplification is that a single size distribution of new particles is commonly used to represent the sub-grid nucleation and growth ("primary sulfate") associated with all $\mathrm{SO}_{2}$ emitted from anthropogenic sources under all atmospheric conditions. For example, some models (e.g. Makkonen et al., 2009) use the assumption recommended by the AeroCom emissions inventory (Dentener et al., 2006) that specifies that all aerosol formation in anthropogenic $\mathrm{SO}_{2}$ source plumes results in new particles having a single accumulation lognormal mode with median radius $500 \mathrm{~nm}$ and a standard deviation of 2.0. In other models (Adams and Seinfeld, 2002, 2003; Pierce and Adams, 2006, 2009; Pierce et al., 2007; Spracklen et al., 2005), the aerosol formed in sub-grid plumes is assumed to have a bi-modal lognormal distribution: a fraction of the particles are emitted as a nucleation mode with geometric number mean diameter $10 \mathrm{~nm}$ and standard deviation 1.6, and the rest are emitted as an Aitken mode with geometric number mean diameter $70 \mathrm{~nm}$ standard deviation 2.0. The fraction of sulfate mass to be emitted into the nucleation mode is also set as $5 \%$ or $15 \%$ depending on the study. Yu and Luo (2009) use yet another assumption; they emit $5 \%$ of the sulfate mass into the nucleation mode described above, and condense the remaining mass onto the existing accumulation mode particles. This approach is more intuitive than the other approaches since some of the sulfate formed in the plume must condense onto pre-existing particles that have been entrained into the plume. A recent paper by Luo and Yu (2011) investigated the effect of varying the fraction of sulfate emitted into the nucleation mode, and found that varying the fraction of sulfate emitted into the nucleation mode from $5 \%$ to $15 \%$ would increase cloud condensation nuclei concentrations at a supersaturation of $0.2 \%$, hereafter denoted as $\mathrm{CCN}(0.2 \%)$, by as much as $18 \%$ over source regions. A major shortcoming of the assumption that the size distribution of new particles is constant is that it will not be representative of all power plants under all atmospheric conditions, as it has been shown that variations in temperature and $\mathrm{OH}$ concentrations would cause the size distribution of aerosol formed to vary seasonally and diurnally (Yu, 2010a).

The second common simplification is that the fraction of $\mathrm{SO}_{2}$ oxidized in the gas phase to form $\mathrm{H}_{2} \mathrm{SO}_{4}$ on the subgrid scale and contributing to primary sulfate is constant for all power plants (and anthropogenic sulfate sources in general) under all atmospheric conditions. Adams and Seinfeld (2003) performed modeling studies to determine the impact on $\mathrm{CCN}(0.2 \%)$ of primary sulfate. They found that if the fraction of anthropogenic $\mathrm{SO}_{2}$ emitted as primary sulfate was changed from $0 \%$ to $3 \%, \mathrm{CCN}(0.2 \%)$ in polluted areas would double. Thus in-plume nucleation increases $\mathrm{CCN}(0.2 \%)$ far more efficiently than does condensation onto pre-existing particles. However, this is likely a maximum effect on $\mathrm{CCN}(0.2 \%)$, as the model did not include organic compounds, dust, or black carbon, only sulfate and sea-salt aerosol. A similar study by Spracklen et al. (2005) also found that increasing the fraction of $\mathrm{SO}_{2}$ emitted as sulfate from $0 \%$ to $3 \%$, would more than double $\mathrm{CCN}(0.2 \%)$ over polluted regions. Wang and Penner (2009) performed another modeling study, where organic matter, black carbon, and dust were also included. They found that if the fraction of $\mathrm{SO}_{2}$ emitted as primary sulfate was increased from $0 \%$ to $2 \%, \mathrm{CCN}(0.2 \%)$ would more than double over polluted areas and would increase by $23 \%$ to $53 \%$ averaged over the global boundary layer (depending on the nucleation scheme used for regional-scale nucleation in the boundary layer). Furthermore, they estimated that the first aerosol indirect effect radiative forcing would increase by $11 \%$ to $31 \%$. Luo and $\mathrm{Yu}$ (2011) found that varying the fraction of sulfur effectively emitted as particles from $0 \%$ to $5 \%$ would increase $\mathrm{CCN}(0.2 \%)$ concentrations globally by $11 \%$ in the boundary layer (Luo and Yu (2011) made a different assumption about the size of these particles than the aforementioned papers, see the previous paragraph). Together, these modeling studies suggest a strong effect on $\mathrm{CCN}$ concentrations and regional radiative forcing to modest changes in sulfur partitioning and the size of particles formed in the plumes of sulfur point sources. 
To better understand the number and size of particles that should be effectively emitted from anthropogenic sources in regional and global models, we explore the evolution of the number and size of sulfate aerosol particles inside coal-fired power-plant plumes using a 3-D fluid-dynamics model of plume chemistry and physics: the System for Atmospheric Modelling (Kairoutdinov and Randall, 2003) with TwO Moment Aerosol Sectional (Adams and Seinfeld, 2002) microphysics (SAM-TOMAS). This model uses a sub-km resolution to resolve the variation of chemistry and physics within the plumes. We test the ability of the model to predict the median diameter and number of particles nucleated within the plumes of two different power plants under different meteorological conditions. We test the sensitivity of the model output to different possible ambient meteorological conditions and background aerosol conditions and show that the resultant size distribution of sulfate aerosol is strongly dependent on these conditions.

The goal of this paper is to test the ability of the SAMTOMAS model to predict new-particle formation and growth in anthropogenic sulfur plumes, determine the number and size of particles formed, and test the sensitivity of the predicted particles to various parameters. Section 2 presents a description of the SAM-TOMAS model. In Sect. 3 we describe the case studies used to evaluate the model, present the results of these evaluations, and assess the performance of the model. Section 4 explores the sensitivity of our modeled results to the nucleation parameterization used, to the background aerosol, and to high and low VOC conditions. Our discussion and conclusions are presented in Sect. 5.

\section{Description of model}

In order to study nucleation and growth in anthropogenic sulfur plumes, we have developed a model that incorporates TwO Moment Aerosol Sectional (TOMAS) (Adams and Seinfeld, 2002) microphysics into the System for Atmospheric Modelling (SAM; Kairoutdinov and Randall, 2003), a Large-Eddy Simulation/Cloud-Resolving Model (LES/CRM). SAM is a flexible fluid dynamics model with a domain that can span tens or hundreds of kilometers, and the individual grid cells can have dimensions between tens of meters to several kilometers. A full description is available in Khairoutdinov and Randall (2003).

The TOMAS microphysics algorithm simulates the aerosol size distribution using fifteen size bins spanning dry diameters of $3 \mathrm{~nm}$ to $10 \mu \mathrm{m}$. In each size bin, TOMAS tracks the number of particles as well as sulfate, ammonium, and water mass. No organic aerosols are included in the model at this time under the assumption that sulfate aerosol formation will be the primary aerosol formation mechanism in the plume; however, we will discuss the uncertainties in this assumption later. TOMAS explicitly calculates coagulation, condensation and nucleation (Adams and Seinfeld, 2002;
Pierce and Adams, 2009). Aerosol growth and coagulational loss below $3 \mathrm{~nm}$ is approximated by the parameterization of Kerminen and Kulmala (2002). This scheme predicts the instantaneous formation for $3 \mathrm{~nm}$ particles based on the nucleation rates (of clusters with diameters closer to $1 \mathrm{~nm}$ ), local growth rates and condensation sinks. Because the growth rates and condensation sinks within the plume may change on timescales faster than the growth time from 1 to $3 \mathrm{~nm}$, the Kerminen and Kulmala (2002) scheme introduces additional uncertainties to our simulations. However, these uncertainties are generally much smaller than the relative uncertainties between the nucleation schemes themselves. Several nucleation schemes are tested and are described in the following paragraph. We simulate gaseous $\mathrm{SO}_{2}, \mathrm{NO}_{\mathrm{x}}$, ammonia $\left(\mathrm{NH}_{3}\right)$ and $\mathrm{H}_{2} \mathrm{SO}_{4}$. We do not explicitly simulate volatile organic compounds (VOCs); however, we test the sensitivity of our results to the effect of high and low VOC concentrations on $\mathrm{OH}$ concentrations (described below). We assume that there are no primary particles emitted directly from the stack, which is consistent with the airborne measurements we use for model evaluation.

We have implemented several different nucleation schemes for use in the model: (1) the classical binary homogeneous nucleation scheme described by Vehkamäki et al. (2002), (2) the ternary $\mathrm{H}_{2} \mathrm{O}-\mathrm{H}_{2} \mathrm{SO}_{4}-\mathrm{NH}_{3}$ nucleation schemes described by Merikanto et al. (2006) and (3) Napari et al. (2002) scaled by a factor of $10^{-4}$ (Westervelt et al., 2011), (4) activation-type nucleation as described by Kulmala et al. (2006), and (5) the ion-mediated nucleation scheme of Yu (2010b). The resulting size distributions predicted by the Merikanto and scaled Napari schemes did not differ significantly, so we only present the results of the Merikanto scheme in this work. In activation-type nucleation, the rate varies as a linear function of the sulfuric acid concentration, according to the following equation (Kumala et al., 2006):

$J=A\left[\mathrm{H}_{2} \mathrm{SO}_{4}\right]$

where $J$ is the nucleation rate, and $A$ is an activation parameter. Unless we specify otherwise (e.g. during the sensitivity analysis), we use $A=10^{-7} \mathrm{~s}^{-1}$ (Sihto et al., 2006).

We use a parameterization to estimate the concentration of $\mathrm{OH}$ in each model grid box based on the concentration of $\mathrm{NO}_{\mathrm{x}}$ in ppbv and the downward shortwave radiative flux (dswrf) in $\mathrm{W} \mathrm{m}^{-2}$. While the $\mathrm{NO}_{\mathrm{x}}$ concentration is used to predict the concentration of $\mathrm{OH}$, we do not currently have a chemical sink for $\mathrm{NO}_{\mathrm{x}}$ in the model, which will lead to an over-prediction of $\mathrm{NO}_{\mathrm{x}}$ later in the plume. The parameterization is an empirical fit to the results of many simulations from the detailed time-dependent photochemical box model described by Olson et al. (2006).

One process not accounted for in the $\mathrm{OH}$ parameterization is the effect of the presence of large amounts of highly reactive VOCs on $\mathrm{OH}$ production. The additional peroxy radicals from isoprene oxidation induce a shift in the peak $\mathrm{OH}$ 
production to a higher $\mathrm{NO}_{\mathrm{x}}$ level. To understand the potential effect of high VOC concentrations in our study, a second parameterization, referred to as the "high-VOC" case, was developed based on an isoprene mixing ratio of $1.5 \mathrm{ppbv}$ (the 95th percentile value observed during INTEX-A). We refer to the original parameterization as the "low-VOC" case. The two parameterizations are outlined in detail in the Appendix.

Dry deposition is not included in the simulations presented here. We tested the sensitivity of the modeled aerosol size distributions to dry deposition by implementing a simple dry deposition scheme. However, even for high deposition velocities, dry deposition had a trivial influence on the size and concentration of particles for the spatial scales we are simulating.

The model meteorology is driven by nudging and boundary conditions from assimilated meteorology from the $\mathrm{Na}$ tional Center for Environmental Prediction (NCEP) North American Regional Reanalysis (NARR) data (Mesinger et al., 2006). The reanalysis data were provided by the National Oceanic and Atmospheric Administration (NOAA), Ocean and Atmospheric Research (OAR), Earth System Research Laboratory (ESRL) Physical Sciences Division (PSD), Boulder, Colorado, USA, from their website at: http://www.esrl. noaa.gov/psd/. NCEP NARR three-hourly assimilation data used in our studies included surface pressure, zonal and meridional wind speed profiles, potential temperature profile, water vapor mixing ratio profile, downward shortwave radiative flux (for $\mathrm{OH}$ calculation), surface sensible heat flux, surface latent heat flux, and surface momentum fluxes. The modeled vertical profiles of temperature, water vapor mixing ratio and horizontal wind speed are nudged to the assimilation profiles on a one-hour time scale. The surface fluxes are prescribed as model boundary conditions. The model turbulent motions (on spatial scales both larger than and smaller than grid box sizes) are freely predicted by SAM and not provided by the NCEP NARR data set.

We obtained the emissions of $\mathrm{SO}_{2}$ and $\mathrm{NO}_{\mathrm{x}}$ from each power plant from Clean Air Markets emissions inventory (Clean Air Markets - Data and Maps, 2010). Background concentrations of $\mathrm{SO}_{2}$ and $\mathrm{NO}_{\mathrm{x}}$, as well as the background size distribution of aerosol, were determined from the inflight measurements either upwind of the power plant or outside of the power-plant plume. In the Parish case (the power plant cases are described in the next paragraph), background values of $\mathrm{NH}_{3}$ were also measured. No measurements of $\mathrm{NH}_{3}$ were available for the Conesville case.

In order to determine the accuracy of our model, we have evaluated the model with airborne data obtained in the plumes of two coal-fired power plants: the W. A. Parish power generation facility near Houston, TX, obtained during the Texas Air Quality Study (TexAQS) 2006 field campaign (Parrish et al., 2009), and the Conesville power generation facility near Conesville, $\mathrm{OH}$ during the International Consortium for Atmospheric Research on Transport and Transformation (ICARTT) campaign (Brown et al., 2007). The observations were taken on board the NOAA WP-3D aircraft. These measured species and the instrumentation used are summarized in Table 1.

The model grid contains 128 grid-boxes in the downwind direction, 60 in the cross-wind direction, and 50 in the vertical direction. We ran the model using $400 \mathrm{~m}$ by $400 \mathrm{~m}$ horizontal resolution, and $800 \mathrm{~m}$ by $800 \mathrm{~m}$ horizontal resolution (we will compare the results of the 2 resolutions). The vertical resolution was always $40 \mathrm{~m}$. Thus the total domain dimensions were $51.2 \mathrm{~km} \times 24 \mathrm{~km} \times 2 \mathrm{~km}$ for the $400 \times 400 \times 40 \mathrm{~m}$ grid-box cases, and $102.4 \mathrm{~km} \times 48 \mathrm{~km} \times 2 \mathrm{~km}$ for the $800 \times 800 \times 40 \mathrm{~m}$ grid-box cases.

\section{Case studies}

\subsection{Parish}

The Parish power generation facility is located $\sim 40 \mathrm{~km}$ southwest of downtown Houston, Texas. The area further south and west of the facility is used for farmland. Five units of the Parish power generation facility were active on 27 September 2006. One of these units had wet lime flue gas desulfurization $\mathrm{SO}_{2}$ controls. Four of the units (including the unit with desulfurization) controlled $\mathrm{NO}_{\mathrm{x}}$ through selective catalytic reduction, and the remaining unit used overfire air for $\mathrm{NO}_{\mathrm{x}}$ controls. Particulate matter was controlled for all units through the use of baghouse filters.

Atmospheric conditions were sunny and clear. The boundary layer was initially stable, becoming unstable between 18:00 GMT and 21:00 GMT, with a depth of $500 \mathrm{~m}$ growing to $1000 \mathrm{~m}$. The wind was blowing from the south at $\sim 5 \mathrm{~m} \mathrm{~s}^{-1}$. The aerosol background was typical of a remote continental region, with three lognormal modes: a small nucleation mode with concentration $1.2 \mathrm{~cm}^{-3}$, median diameter $3.3 \mathrm{~nm}$, and geometric standard deviation 1.3; a wide Aitken mode with concentration $770 \mathrm{~cm}^{-3}$, median diameter $89 \mathrm{~nm}$, and geometric standard deviation 2.8; and an accumulation mode with concentration $640 \mathrm{~cm}^{-3}$, median diameter $120 \mathrm{~nm}$, and geometric standard deviation 1.3.

We show the predicted instantaneous nucleation rates as a function of height and distance from the source along the center of the plume in Fig. 1a, and as a function of crosswind distance and distance from the source at an altitude of $460 \mathrm{~m}$ in Fig. 1b. This figure can be considered a "snapshot" of the nucleation rates within the modeled plume at a single point in time. (All other figures in this work present the concentrations of aerosol or gas species time-averaged over a period of $\sim 2.2 \mathrm{~h}$.) In the first $1-2 \mathrm{~km}$, nucleation is suppressed because $\mathrm{OH}$ concentrations are very low due to high $\mathrm{NO}_{\mathrm{x}}$ concentrations. As the initial high $\mathrm{NO}_{\mathrm{x}}$ concentrations become diluted, nucleation rates reach a maximum around $5 \mathrm{~km}$ from the source. Nucleation rates decrease further downwind of the source as the condensation sink increases and $\mathrm{SO}_{2}$ 
Table 1. Measurements and instrumentation for each investigated power plant.

\begin{tabular}{lll}
\hline & Parish & Conesville \\
\hline $\mathrm{NO}$ & $\mathrm{O}_{3}$-induced CL & $\mathrm{O}_{3}$-induced CL \\
$\mathrm{NO}_{2}$ & $\mathrm{UV}^{2}$ photolysis-CL & UV photolysis-CL \\
$\mathrm{SO}_{2}$ & Pulsed UV fluorescence & Pulsed UV fluorescence \\
$\mathrm{NH}_{3}$ & Protonated acetone dimer CIMS & Not available \\
$\mathrm{H}_{2} \mathrm{SO}_{4}$ & $\mathrm{NO}_{3}^{-}$CIMS & $\mathrm{NO}_{3}^{-}$CIMS \\
\hline $\begin{array}{l}\text { Aerosol number, size and } \\
\text { volume distributions }\end{array}$ & White and laser light in parallel & $\begin{array}{l}\text { Laser light scattering and } \\
\text { five CPCs in parallel behind }\end{array}$ \\
& scattering and five CPC & a low turbulence inlet \\
\hline
\end{tabular}

${ }^{1} \mathrm{CL}$ - chemiluminescence, ${ }^{2} \mathrm{UV}$ - ultraviolet, ${ }^{3} \mathrm{CIMS}$ - chemical ionization mass spectrometry, ${ }^{4} \mathrm{CPC}$ - condensation particle counter.

concentrations decrease (primarily due to dilution), but are elevated where the polluted boundary-layer air mixes with the clean air of the free troposphere due to the reduced condensation sink in this region. In general, we see enhanced nucleation where high concentrations of $\mathrm{H}_{2} \mathrm{SO}_{4}$ formed within the plume and the lower condensation sink and $\mathrm{NO}_{\mathrm{x}}$ outside of the plume coincide due to turbulent mixing. These turbulent eddies create regions within the plume with especially high and low concentrations of $\mathrm{NO}_{\mathrm{x}}$ and $\mathrm{SO}_{2}$ that alter the nucleation rate within the plume. This in turn causes the contribution of nucleation to the condensation sink to be inhomogeneous within the plume. As seen in Fig. 1, these turbulent mixing effects can cause the nucleation rate to vary by a factor of two within the plume, even at the same distance from the source. These inhomogeneous regions of enhanced nucleation, evident at the downwind plume edges, cannot be resolved using a model that assumes a pre-defined Gaussian plume, which has motivated the choice of an LES/CRM model that represents turbulent motion for this study.

Figure 2 compares observed and modeled gas and particle concentrations for an aircraft transect through the plume $\sim 36 \mathrm{~km}$ from the power plant. Figure $2 \mathrm{a}$ shows the measured and modeled gas concentrations as the aircraft flew across the plume, and Fig. $2 \mathrm{~b}$ and $\mathrm{c}$ shows the observed and modeled size distributions, respectively. We see that the width of the modeled plume agrees with the width of the observed plume, but the predicted concentration of $\mathrm{NO}_{\mathrm{x}}$ is too large at the center of the plume by $\sim 4 \mathrm{ppb}$. Our predicted concentrations of $\mathrm{H}_{2} \mathrm{SO}_{4}$ and $\mathrm{SO}_{2}$ agree with the observed concentrations, within their respective variabilities. We note that there is a peak in the observed $\mathrm{NO}_{\mathrm{x}}$ concentrations $\sim 2 \mathrm{~km}$ from the plume center, and that this peak coincides with the location of a major multilane highway, the Sam Houston Tollway. We therefore believe that this peak is due to vehicle emissions, which are not explicitly simulated within the model. The model slightly under-predicts the peak diameter of the aerosol size distribution as $\sim 30 \mathrm{~nm}$, compared to the observed peak diameter of $\sim 50 \mathrm{~nm}$. The number concentration of aerosol at the peak within the plume is very close to the observed value, but the number concentration of particles smaller than $100 \mathrm{~nm}$ outside of the plume is under-predicted. We do not explicitly simulate any other sources of particles or gases within the model domain aside from the power plant, and this may explain the discrepancy outside of the plume.

We show the observed and modeled trace-gas concentrations with distance from the power plant, averaged over the plume cross section, in Fig. 3a. We consider a point along a transect to be within the plume if the concentration of $\mathrm{SO}_{2}$ at that point is greater than $33 \%$ of the maximum concentration of $\mathrm{SO}_{2}$ found along that transect, after subtracting out the background concentration. $\mathrm{NO}_{\mathrm{x}}$ measurements were unavailable inside the plume for the fourth transect, so no observed value for $\mathrm{NO}_{\mathrm{x}}$ is plotted for this transect. The results from the model using $800 \times 800 \times 40 \mathrm{~m}$ resolution are shown as a solid line, and the $400 \times 400 \times 40 \mathrm{~m}$ resolution results are shown as a dashed line. We note that the $800 \times 800 \times 40 \mathrm{~m}$ mixing ratios of $\mathrm{NO}_{\mathrm{x}}$ and $\mathrm{SO}_{2}$ are $\sim 1$ ppbv and $\sim 5$ ppbv lower than the $400 \times 400 \times 40 \mathrm{~m}$ mixing ratios, respectively, but the $\mathrm{H}_{2} \mathrm{SO}_{4}$ concentrations are quite similar between the two cases. Differences in these values between the two resolutions are similar when applied to the Conesville case (not shown). When the $\mathrm{SO}_{2}$ and $\mathrm{NO}_{\mathrm{x}}$ are initially emitted into the model domain, they are immediately diluted to be uniformly mixed within a single grid-box. Concentrations of $\mathrm{SO}_{2}$ and $\mathrm{NO}_{\mathrm{x}}$ are consequently slightly lower in the $800 \times 800 \times 40 \mathrm{~m}$ than in the $400 \times 400 \times 40 \mathrm{~m}$ resolution model. These variations in the concentrations of gaseous species due to altering the model resolution between $400 \times 400 \times 40 \mathrm{~m}$ and $800 \times 800 \times 40 \mathrm{~m}$ are similar in magnitude to variations due to across-plume turbulence, and it does not appear that the accuracy of the model will be greatly improved by using resolutions finer than $800 \times 800 \times 40 \mathrm{~m}$. In the following discussion, we will consider the results of the $800 \times 800 \times 40 \mathrm{~m}$ resolution model, as this allows for comparison with the observations further than $50 \mathrm{~km}$ from the source.

At the first transect, $\sim 5.4 \mathrm{~km}$ downwind from the power plant, we overestimate the concentrations of $\mathrm{NO}_{\mathrm{x}}$ by 


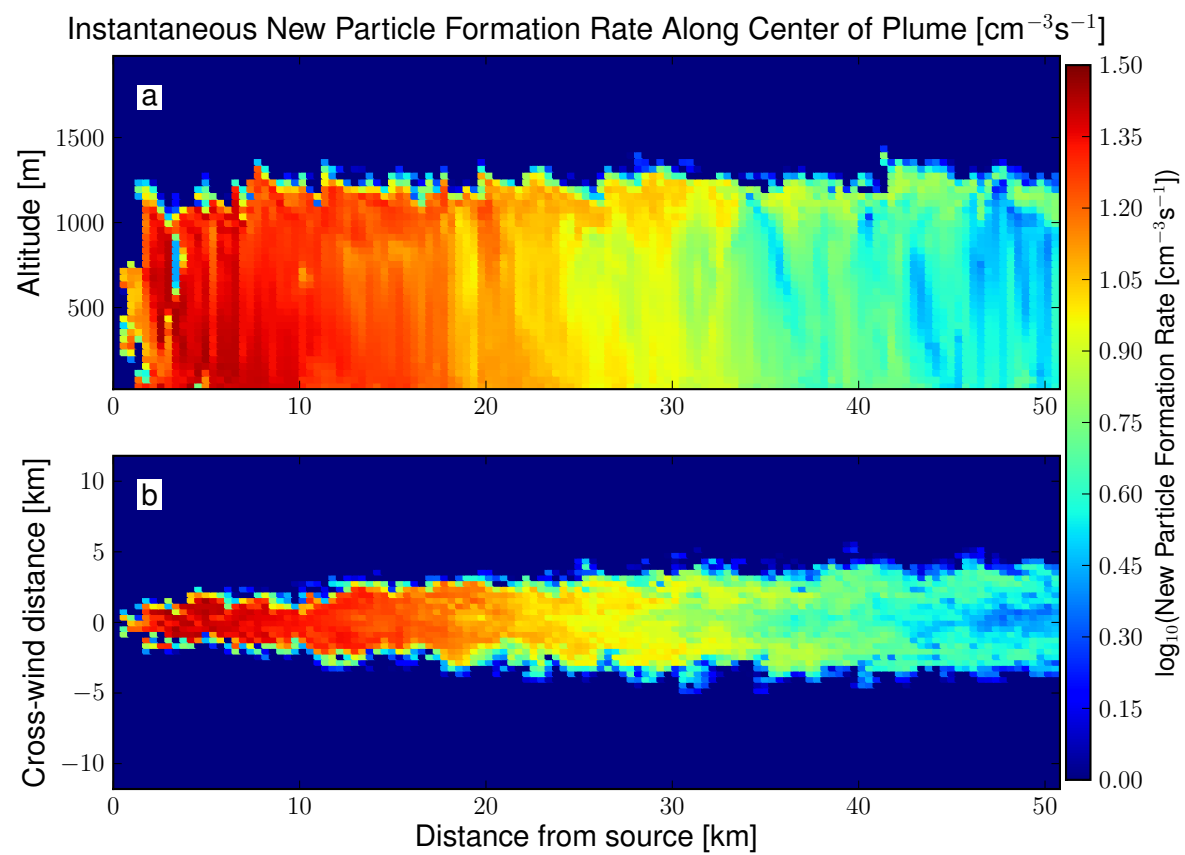

Fig. 1. Instantaneous snapshot of new-particle formation rates of the modeled Parish plume (a) along the cross-wind center and (b) at an altitude of $460 \mathrm{~m}$. Model resolution is $400 \times 400 \times 40 \mathrm{~m}$.
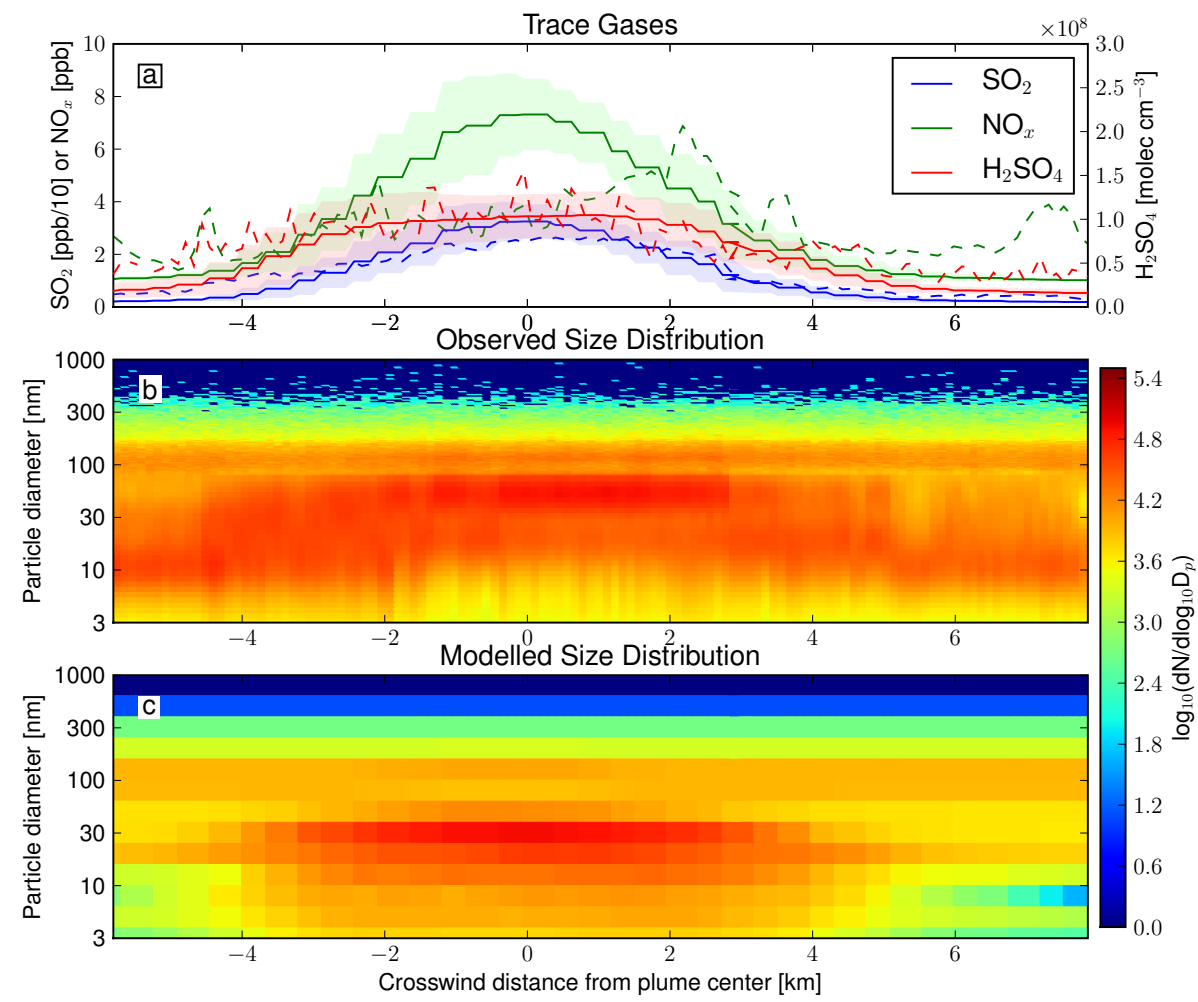

Fig. 2. Trace gas and aerosol concentrations along the second transect north of Parish, about $36 \mathrm{~km}$ from the power-plant. X-axes show flight track through cross-wind slice of plume. Model resolution is $400 \times 400 \times 40 \mathrm{~m}$. (a) Trace gas concentrations. Observed concentrations as dashed lines, model results as solid lines. Shaded area indicates one standard deviation of the model results, due to turbulent fluctuations. (b) Observed aerosol number size distribution. (c) Modeled aerosol number size distribution. 

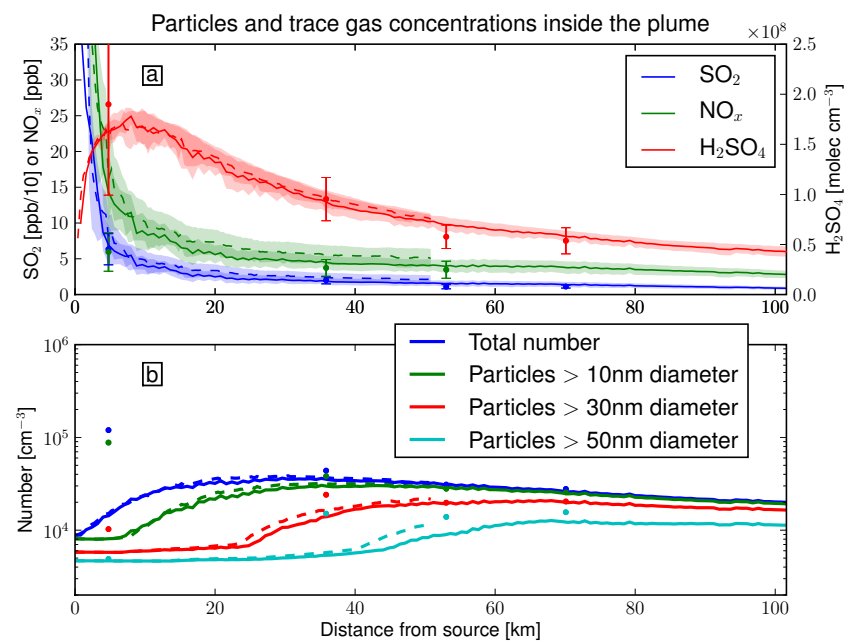

Fig. 3. (a) Trace gases and (b) particle number vs. distance downwind from the Parish power-plant, averaged over plume. Dots are aircraft observations; lines are model results. Shaded area and error bars indicate one standard deviation in concentration across plume width. Solid lines indicate $800 \times 800 \times 40 \mathrm{~m}$ model resolution; dashed lines indicate $400 \times 400 \times 40 \mathrm{~m}$ model resolution.

$\sim 10 \mathrm{ppb}$, but we accurately predict the concentrations of $\mathrm{SO}_{2}$ and $\mathrm{H}_{2} \mathrm{SO}_{4}$. At the remaining transects, $\sim 36, \sim 54, \sim 71$, and $\sim 94 \mathrm{~km}$ from the source, the predicted concentrations of $\mathrm{NO}_{\mathrm{x}}$ are within $1 \mathrm{ppb}$ of the observed values, and we continue to accurately predict $\mathrm{SO}_{2}$ and $\mathrm{H}_{2} \mathrm{SO}_{4}$.

We show the observed and modeled number concentrations with distance from the power plant in Fig. $3 b$. The particles in the $400 \times 400 \times 40 \mathrm{~m}$ resolution simulation grow slightly faster than those in $800 \times 800 \times 40 \mathrm{~m}$ resolution simulation, but we note that the disagreement between the results for each model resolution is less than a factor of 1.5 for any given size range at all downwind distances. We will show in Sect. 4 that the uncertainties in aerosol concentrations due to the choice of nucleation parameterization or due to uncertainties in the effects of VOCs upon $\mathrm{OH}$ concentrations are comparable or larger in magnitude, and thus we feel that the accuracy of the model results will not be improved by the choice of a finer model resolution until the level of scientific understanding of these processes has advanced. At the first transect, $\sim 5.4 \mathrm{~km}$ from the source, the nucleated aerosol particles have not yet grown beyond $50 \mathrm{~nm}$ in either the model or the observations, and so the numbers of particles with diameters larger than $50 \mathrm{~nm}$ predicted by the model and observed differ by less than $5 \%$. However, the observed particles have grown larger than $30 \mathrm{~nm}$, while the modeled particles have only grown to $\sim 10 \mathrm{~nm}$. The total number of nucleated particles is also almost an order of magnitude smaller in the model than in the observations. At $\sim 35 \mathrm{~km}$ downwind of the source the model under-predicts the number of particles in each size range. The model under-predicts the number of particles with diameters larger than $50 \mathrm{~nm}$ because the newly-formed parti- cles in the model have only grown to a diameter of $\sim 30 \mathrm{~nm}$, whereas some of the observed particles have already grown larger than $50 \mathrm{~nm}$. The model under-estimates concentrations of particles smaller than $50 \mathrm{~nm}$ in diameter by less than a factor of 2. The modeled concentrations of particles smaller than $50 \mathrm{~nm}$ are within $10 \%$ of the observed concentrations at the remaining transects, and the modeled concentrations of particles larger than $50 \mathrm{~nm}$ in diameter are $36 \%$ and $22 \%$ lower than the observed values at the third and fourth transects, respectively. These results show that for the Parish case, the SAM-TOMAS model does a decent job of predicting the particle size distributions for distances from the source that are relevant for "effective emissions" in regional and global models.

The discrepancies between the model results and the observations for the first two transects may be explained by nucleation occurring very close to or within the power plant stack. Due to the high $\mathrm{NO}_{\mathrm{x}}$ concentrations near the stack, the predicted $\mathrm{OH}$ concentrations are low in this region and $\mathrm{SO}_{2}$ oxidation is initially predicted to be slow; thus the model does not predict a high initial nucleation rate. We suggest two possible ways by which sufficiently high concentrations of $\mathrm{H}_{2} \mathrm{SO}_{4}$ for nucleation and particle growth may be forming within or close to the stack: First, there may be formation of sulfur trioxide $\left(\mathrm{SO}_{3}\right)$ in the power plant, which would quickly form $\mathrm{H}_{2} \mathrm{SO}_{4}$ in the stack (the nucleation might be occurring in the stack or shortly thereafter; Mueller and Imhoff, 1994; Srivastava et al., 2004; Cichanowicz, 2007; Zaveri et al., 2010). Secondly, HONO that is emitted from the stack would be a source of $\mathrm{OH}$ near the stack, and thus increase the oxidation of $\mathrm{SO}_{2}$ to form $\mathrm{H}_{2} \mathrm{SO}_{4}$ in the region of our predicted OH minima (Kleffmann, 2007). While direct emission of $\mathrm{HONO}$ would provide a brief burst of $\mathrm{OH}$, evidence for sustained HONO production through heterogeneous chemistry has also been observed in polluted environments such as Houston, TX (Olaguer et al., 2009) and Mexico City (Li et al., 2010; Volkamer et al., 2010). Although this chemistry is not well understood and is often related to organic aerosols, it could be relevant to power-plant plumes where high surface area is available to drive $\mathrm{HONO}$ formation providing additional $\mathrm{OH}$ and accelerating $\mathrm{SO}_{2}$ oxidation.

A useful value for global and regional models is the number of particles formed per mass of $\mathrm{SO}_{2}$ emitted. These values may be used as sub-grid nucleation or effective primary sulfate emissions in these models. We approximate this value in the model by subtracting the original background concentrations from the particle number concentration, and then we divide this by the background-corrected $\mathrm{SO}_{2}$ mass concentrations and integrate across the plume. These values are shown as a function of downwind distance in Fig. 4. At distances greater than $60 \mathrm{~km}$ downwind of the source, the values stabilize near an additional $2 \times 10^{17}$ total particles per $\mathrm{kg} \mathrm{SO}_{2}$, of which half are larger than $50 \mathrm{~nm}$. Nearly all of the particles have grown larger than $30 \mathrm{~nm}$. 


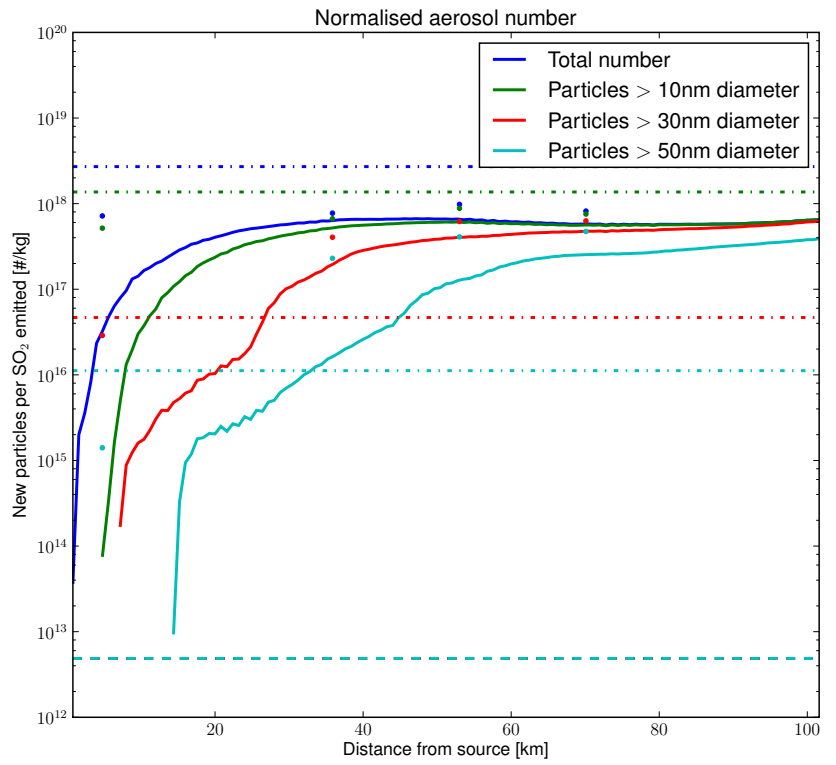

Fig. 4. Additional predicted particles per $\mathrm{kg} \mathrm{SO}_{2}$ versus distance from the Parish power plant, summed over the plume. Model resolution is $800 \times 800 \times 40 \mathrm{~m}$. Dots indicate aircraft observations, solid lines indicate model results, dashed lines indicate the values used by Dentener et al. (2006), and dashed-dotted lines indicate the values used by Adams and Seinfeld (2003). Coloring indicates size range of particles. Essentially all particles in the Dentener et al. (2006) distribution are larger than $50 \mathrm{~nm}$, so all dashed lines overlap one another.

For comparison, we also plot number of particles per $\mathrm{kg} \mathrm{SO} 2$ that would result from the primary sulfate size distributions used in the AeroCom data set (Dentener et al., 2006) and in Adams and Seinfeld (2003). We note that the stable values reached by our model are several orders of magnitude greater than the value from Dentener et al. (2006). This is because the model predicts that most new particles nucleated within the plume will grow to sizes less than $50 \mathrm{~nm}$, while Dentener et al. (2006) select a median diameter of $1 \mu \mathrm{m}$, yielding a much smaller number of much larger particles. The stable value for total particles reached by the model is less than a third of that from Adams and Seinfeld (2003), but we predict an order of magnitude more particles larger than $30 \mathrm{~nm}$ and almost two orders of magnitude more particles larger than $50 \mathrm{~nm}$. This indicates that Adams and Seinfeld use a size distribution that includes a much larger fraction of particle number at sizes smaller than $30 \mathrm{~nm}$ than our model predicts for the specific case of the Parish power plant.

As noted in Sect. 1, regional and global models commonly assume that a constant fraction of $\mathrm{SO}_{2}$ emitted from the power plant will oxidize to form $\mathrm{H}_{2} \mathrm{SO}_{4}$ and that a constant fraction of this $\mathrm{H}_{2} \mathrm{SO}_{4}$ condenses to new particles rather than pre-existing particles. In Table 2, we show the fraction of the emitted $\mathrm{SO}_{2}$ that has oxidized to form $\mathrm{H}_{2} \mathrm{SO}_{4}$ within $50 \mathrm{~km}$ of the source for each case and the fraction of the sulfate formed that has gone into the nucleation or growth of new particles within $50 \mathrm{~km}$ of the source for each case. For the base Parish case, we find that $9 \%$ of the emitted $\mathrm{SO}_{2}$ is converted into sulfate within $50 \mathrm{~km}$ of the source, climbing to $26 \%$ within $100 \mathrm{~km}$. We note that these numbers are greater than the fraction of $\mathrm{SO}_{2}$ that is emitted as "primary sulfate" from power plants in global models, which is generally $5 \%$ or less (Adams and Seinfeld, 2003; Spracklen et al., 2005; Wang and Penner, 2009; Luo and Yu, 2011), and that the horizontal resolution in such models would generally be $100 \mathrm{~s}$ of $\mathrm{km}$. However, this Parish case is a sunny summer daytime case, which should favor the highest amount of sub-grid oxidation, whereas the global models chose a representative average value. Furthermore, the emitted $\mathrm{SO}_{2}$ in global models that is not oxidized immediately will continue to oxidize in subsequent time steps, so this low bias on sunny days may be partially corrected for in the global models. Our model also predicts that $21 \%$ of the sulfate mass will form or condense onto new particles within $50 \mathrm{~km}$ from the source. This is at the upper range of assumptions used for the fraction of sulfate mass that condenses onto new particles in global models (Luo and Yu, 2011). However, both the fraction of $\mathrm{SO}_{2}$ that oxidizes and the fraction of sulfate mass that forms new particles are dependent on the conditions of each power-plant case. We will explore the effects of changing some of these conditions in Sect. 4.

\subsection{Conesville}

The Conesville power generation facility is located in a valley along the Muskingham river in Ohio, in a heavily forested region in the North-Eastern United States. Of the four units in operation on 6 August 2004, two had wet lime flue gas desulfurization $\mathrm{SO}_{2}$ controls and low $\mathrm{NO}_{\mathrm{x}}$ burner technology with separated overfire air, and one had only low $\mathrm{NO}_{\mathrm{x}}$ burner technology (dry bottom only). All units had electrostatic precipitators.

During the time of the measurement there was an unstable boundary layer that was $\sim 1300 \mathrm{~m}$ deep and was capped by broken clouds. The wind was from the north at $\sim 5 \mathrm{~m} \mathrm{~s}^{-1}$. The aerosol background was typical of a rural continental area with an Aitken peak with $d \mathrm{~N} / d \log _{10} D_{\mathrm{p}} \sim$ $2 \times 10^{4} \mathrm{~cm}^{-3}$ at $20 \mathrm{~nm}$ and $d \mathrm{~N} / d \log _{10} D_{\mathrm{p}} \sim 5 \times 10^{3} \mathrm{~cm}^{-3}$ at particle diameters away from this peak up to $200 \mathrm{~nm}$. Above $200 \mathrm{~nm}$ the aerosol concentrations decreased. The total number concentration was $1.7 \times 10^{4} \mathrm{~cm}^{-3}$. The average background mixing ratios of $\mathrm{SO}_{2}$ and $\mathrm{NO}_{\mathrm{x}}$ measured were $\sim 0.6 \mathrm{ppbv}$ and $\sim 1.6 \mathrm{ppbv}$, respectively.

The measurements and model predictions of gas-phase $\mathrm{SO}_{2}, \mathrm{NO}_{\mathrm{x}}$, and $\mathrm{H}_{2} \mathrm{SO}_{4}$ along the first transect, $\sim 24 \mathrm{~km}$ from the source, are shown in Fig. 5a. The modeled values are shown as solid lines, and the measured concentrations of $\mathrm{NO}_{\mathrm{x}}$ and $\mathrm{SO}_{2}$ are shown as dashed lines. The measured values of $\mathrm{H}_{2} \mathrm{SO}_{4}$ are shown as dots in this figure in order 
Table 2. Fraction of $\mathrm{SO}_{2}$ oxidized and fraction of produced $\mathrm{H}_{2} \mathrm{SO}_{4}$ that condenses onto new particles rather than pre-existing particles within $50 \mathrm{~km}$ for each model simulation. The labels $400 \times 400 \times 40 \mathrm{~m}$ and $800 \times 800 \times 40 \mathrm{~m}$ refer to the two model resolutions used in this study. The A-6, Vehk, Meri, and Yu10 nucleation schemes are discussed in Sect. 4.1. The REM, MAR, and URB aerosol backgrounds are discussed in Sect. 4.2. The sunny and cloudy cases and the high-VOC and low-VOC cases are discussed in Sect. 4.3.

\begin{tabular}{lrr}
\hline & Fraction of $\mathrm{SO}_{2}$ oxidized & $\begin{array}{r}\text { Fraction of produced } \mathrm{H}_{2} \mathrm{SO}_{4} \text { that } \\
\text { condenses onto new particles } \\
\text { rather than pre-existing particles }\end{array}$ \\
\hline Parish base case & $9 \%$ & $21 \%$ \\
$(400 \times 400 \times 40 \mathrm{~m}, \mathrm{REM}$-sunny, & & \\
$A-7$, high-VOC) & & $18 \%$ \\
Parish $(800 \times 800 \times 40 \mathrm{~m})$ & $11 \%$ & $33 \%$ \\
Parish A-6 & $9 \%$ & $\ll 1 \%$ \\
Parish Vehk & $9 \%$ & $42 \%$ \\
Parish Meri & $9 \%$ & $13 \%$ \\
Parish Yu10 & $9 \%$ & $\ll 1 \%$ \\
Parish REM-cloudy & $0.8 \%$ & $90 \%$ \\
Parish MAR-sunny & $9 \%$ & $75 \%$ \\
Parish MAR-cloudy & $0.8 \%$ & $\ll 1 \%$ \\
Parish URB-sunny & $9 \%$ & $\ll 1 \%$ \\
Parish URB-cloudy & $0.8 \%$ & $9 \%$ \\
Parish low-VOC & $6 \%$ & $13 \%$ \\
Conesville $(400 \times 400 \times 40 \mathrm{~m})$ & $4 \%$ & $12 \%$ \\
Conesville $(800 \times 800 \times 40 \mathrm{~m})$ & $4 \%$ & \\
\hline
\end{tabular}

to indicate the lower time resolution of those measurements. The observations show two separate plumes along this transect, which cannot be predicted by the current version of the model. The two plumes are also visible in the observed size distribution, shown in Fig. 5b. The $\mathrm{SO}_{2}-\mathrm{NO}_{\mathrm{x}}$ ratios for the two plumes are similar, and neither plume was observed upwind of the power plant, which leads us to believe that both plumes originate from the Conesville power plant. Since the power-plant stacks are much closer than the distance between the center of the plumes $(\sim 3 \mathrm{~km})$, the plume must have bifurcated either due to complex flows at the stack (Fanaki, 1975) or due to topographic effects from hills in the region. The boundary layer at the Conesville power generation facility was very stable until sunrise, $\sim 5 \mathrm{~h}$ before the observations were made, which may favor bifurcation of the plume at the stack. We note that the plume width and the mixing ratios of $\mathrm{NO}_{\mathrm{x}}$ and $\mathrm{SO}_{2}$ predicted by the model do agree well with those observed in either of the two plumes, although the model predictions of $\mathrm{H}_{2} \mathrm{SO}_{4}$ were about double those of the measurements. If both plumes are due to the Conesville power plant, then it would seem that roughly half the mass of $\mathrm{SO}_{2}$ and $\mathrm{NO}_{\mathrm{x}}$ are missing from the model predictions. This may be due to an inaccuracy in the emissions that we use in the model or an incorrect prediction of the boundary-layer height in the model. If the predicted boundary-layer height was too large, the actual emissions from the power plant would be vertically diluted to a greater extent in the model, which would yield lower mix- ing ratios along the transect. Integrating the mixing ratios of $\mathrm{NO}_{\mathrm{x}}$ and $\mathrm{SO}_{2}$ across the second and third (farther) transects yields much smaller discrepancies than those observed at the first transect. The separation of the two plumes is less distinct at the second transect, $\sim 40 \mathrm{~km}$ from the source, in both the trace gas observations and the aerosol size distribution (not shown). Under unstable conditions, vertical shear in wind direction and turbulent diffusion is likely to mix two adjacent plumes together.

The modeled number distribution for the first transect south of Conesville is shown in Fig. 5c. The peak at $\sim 20 \mathrm{~nm}$ matches the peak in the observed number distribution. However, there is an observed increase within the plume in the number of particles with diameters between $40 \mathrm{~nm}$ and $200 \mathrm{~nm}$ that is not predicted by the model. In Fig. 6b, we show the total number concentration, and the number concentration of particles larger than 10,30 , and $50 \mathrm{~nm}$ in diameter. The unpredicted increase in $40 \mathrm{~nm}$ to $200 \mathrm{~nm}$ particles is responsible for the under-prediction of particles larger than 30 and $50 \mathrm{~nm}$ at the first and second transects. By the third transect, a significant fraction of the particles from the initial nucleation burst have grown larger than $30 \mathrm{~nm}$, and as these particles from the nucleation burst now dominate the number concentration in this size range, the model predictions are within $1 \%$ of the observed number concentration of particles larger than $30 \mathrm{~nm}$. As in the Parish case, the model predictions for number concentrations of all but the largest particles agree well (within 10\%) with the observations beyond 

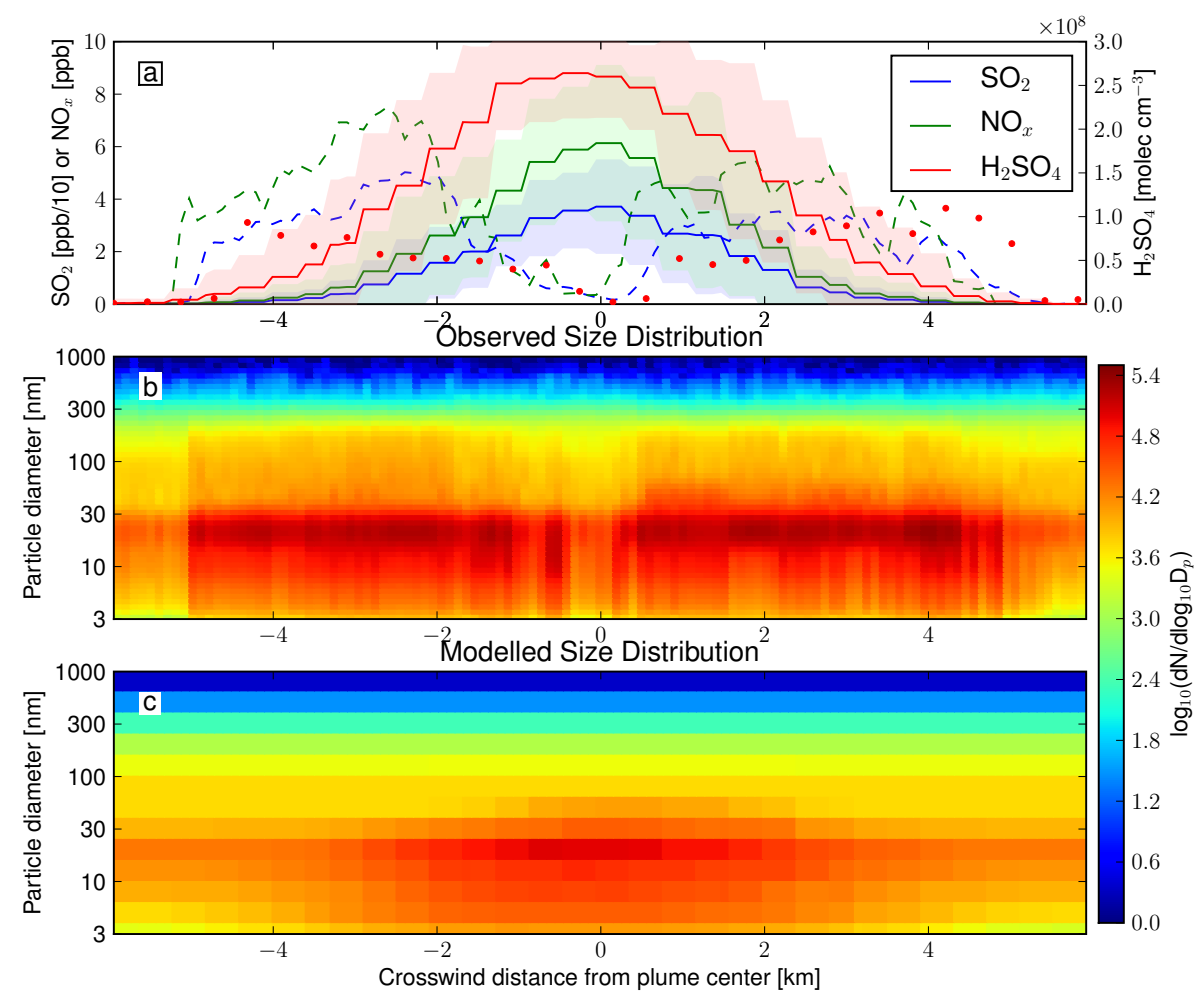

Fig. 5. Trace gas and aerosol concentrations along the first transect south of Conesville, about $24 \mathrm{~km}$ from the power-plant. X-axes show flight track through cross-wind slice of plume. Model resolution is $400 \times 400 \times 40 \mathrm{~m}$. (a) Trace gas concentrations. Observed concentrations as dashed lines $\left(\mathrm{SO}_{2}\right.$ and $\left.\mathrm{NO}_{\mathrm{x}}\right)$ and dots $\left(\mathrm{H}_{2} \mathrm{SO}_{4}\right)$, model results as a solid line. Shaded area indicates one standard deviation of the model results, due to turbulent fluctuations. (b) Observed aerosol number size distribution. (c) Modeled aerosol number size distribution.
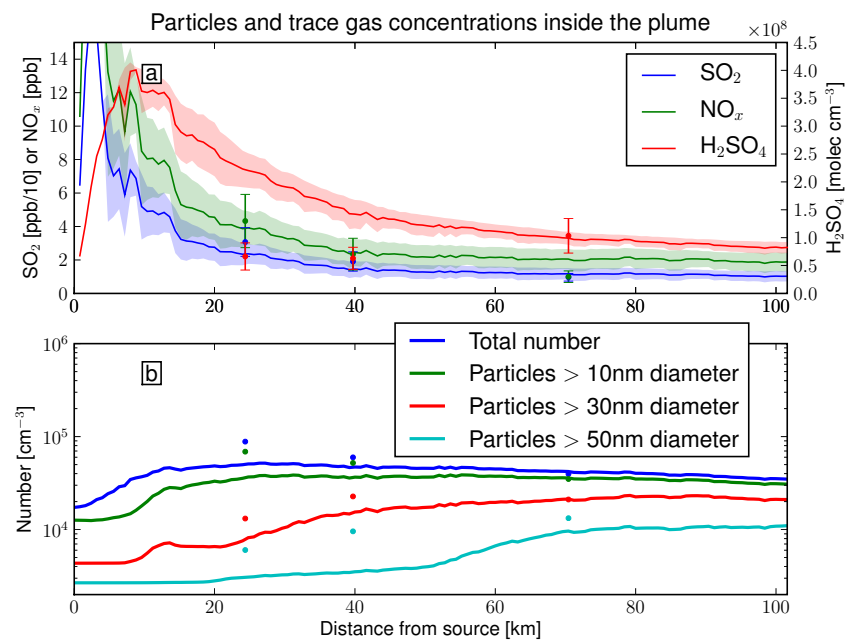

Fig. 6. (a) Trace gases and (b) particle number versus distance downwind from the Conesville power-plant, averaged over the plume. Dots are aircraft observations; lines are model results. Shaded area and error bars indicate one standard deviation in concentration across plume width. Model resolution is $800 \times 800 \times 40 \mathrm{~m}$.
$50 \mathrm{~km}$ from the power plant, although the concentrations of particles larger than $50 \mathrm{~nm}$ are under-predicted by $27 \%$.

The concentrations of trace gases with distance from the power plant are shown in Fig. 6a. The concentrations of $\mathrm{SO}_{2}$ and $\mathrm{NO}_{\mathrm{x}}$ for the first two transects are well predicted by the model. At the third transect, $\sim 68 \mathrm{~km}$ from the source, the observed plume is much wider and more dilute than the modeled plume, and as a consequence, the model overpredicts the $\mathrm{NO}_{\mathrm{x}}$ concentrations within the plume. We see the opposite trend in $\mathrm{H}_{2} \mathrm{SO}_{4}$ concentrations: the model overpredicted the concentrations of $\mathrm{H}_{2} \mathrm{SO}_{4}$ for the first two transects, but the observed concentration of $\mathrm{H}_{2} \mathrm{SO}_{4}$ increases at the third transect, and the modeled concentration agrees well with this observed value. An over-prediction of $\mathrm{H}_{2} \mathrm{SO}_{4}$ would yield larger nucleation and growth rates of aerosol particles, and thus should increase particle number concentrations. However, as discussed above, the predicted particle number concentrations at the first two transects are less than those observed in each size range. There are several possible explanations for these seemingly contradictory features. During the measurement campaign, there were broken clouds present, which would make the penetration of UV radiation into the boundary layer highly variable in space and time. Consequently, $\mathrm{OH}$ production rates, and thus $\mathrm{H}_{2} \mathrm{SO}_{4}$ 
production rates would be highly variable in space and time. It is possible that at the time of measurement of the first two transects, cloudy conditions had lowered the $\mathrm{OH}$ production rate, and the $\mathrm{H}_{2} \mathrm{SO}_{4}$ concentration had been depleted below the mean concentration at those locations. We will discuss further the effects of cloudy conditions upon sulfate production in Sect. 4.3. It is also possible that the effect of the overprediction of $\mathrm{H}_{2} \mathrm{SO}_{4}$ upon aerosol concentrations has been compensated by an under-prediction of the nucleation rate. We will show in Sect. 4.1 that the predicted aerosol number concentrations could increase if a different nucleation parameterization was used.

Figure 7 shows that the predicted change in the number of particles per additional mass of $\mathrm{SO}_{2}$ stabilizes at distances greater than $70 \mathrm{~km}$ from the power plant at an additional $6 \times 10^{17}$ total particles per $\mathrm{kg} \mathrm{SO}_{2}$. Almost all of these particles have grown to diameters larger than $30 \mathrm{~nm}$ by this distance, and half are larger than $50 \mathrm{~nm}$. However, as the model predicts fewer particles larger than $50 \mathrm{~nm}$ than are observed, it also predicts fewer additional particles larger than $50 \mathrm{~nm} \mathrm{~kg}^{-1} \mathrm{SO}_{2}$ than are observed. These results are remarkably similar to those obtained for the Parish case. As total $\mathrm{SO}_{2}$ emissions were much higher in the Conesville case than in the Parish case, the predicted concentrations of $\mathrm{H}_{2} \mathrm{SO}_{4}$ were $\sim 2$ times larger than in the Parish case even though a smaller fraction of the emitted $\mathrm{SO}_{2}$ formed $\mathrm{H}_{2} \mathrm{SO}_{4}$ (this is due to a lower shortwave radiative flux; Table 2). This, along with a lower condensation sink than in the Parish case, resulted in faster new-particle formation, and more than twice as many new particles being formed in the Conesville case. Thus the number of particles per $\mathrm{kg} \mathrm{SO}_{2}$ was similar between cases. Both observations and models indicate several orders of magnitude more particles per $\mathrm{kg} \mathrm{SO}_{2}$ in the Conesville case than suggested by Dentener et al. (2006), and less than one third of the particles per $\mathrm{kg}$ of $\mathrm{SO}_{2}$ emitted suggested by Adams and Seinfeld (2003).

The fraction of produced sulfuric acid that formed or condensed onto new particles (as opposed to condensing onto pre-existing particles) was somewhat less in the Conesville case $(13 \%)$ than that in the Parish case (21\%; Table 2). While more particles form in the Conesville case, more of the particles in the Parish case grow beyond $50 \mathrm{~nm}$, and the largest of the newly-formed particles constitute a disproportionately large fraction of the condensation sink. Thus the ratio of the condensation sink of the new particles to the preexisting particles is less in the Conesville case, and this in turn causes less of the $\mathrm{H}_{2} \mathrm{SO}_{4}$ to condense onto the new particles in the Conesville case than in the Parish case.

\section{Sensitivity studies}

In this section, we will explore how uncertainties in model inputs as well as variability in atmospheric conditions affect the predicted nucleation and growth in the Parish plume.

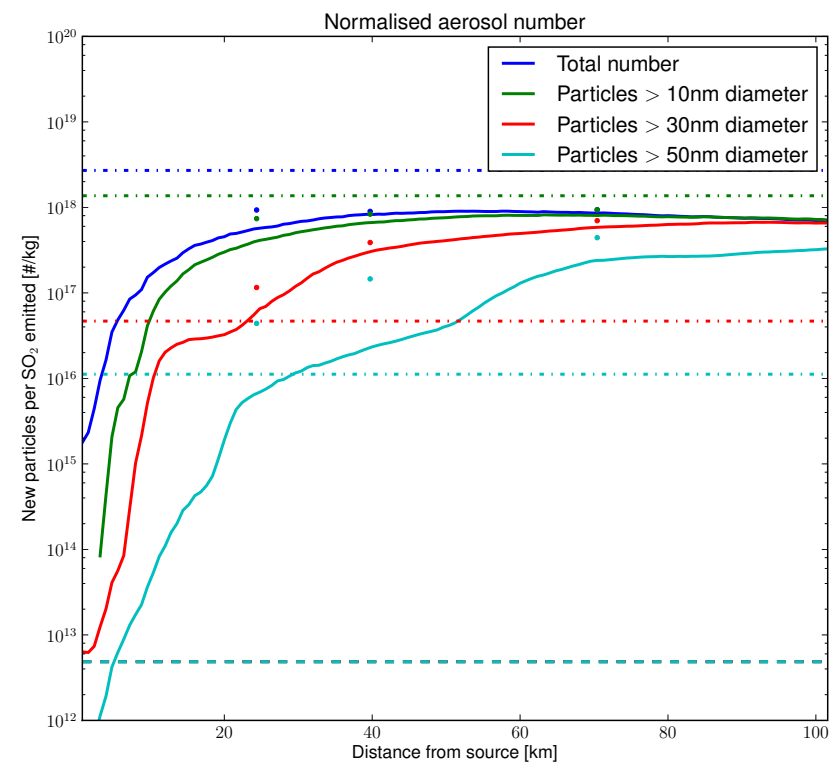

Fig. 7. Additional predicted particles per $\mathrm{kg} \mathrm{SO}_{2}$ emitted versus distance from the Conesville power-plant, summed over the plume. See Sect. 3.1 for a description of the calculation. Model resolution is $800 \times 800 \times 40 \mathrm{~m}$. Dots indicate aircraft observations, solid lines indicate model results, dashed lines indicate the values used by Dentener et al. (2006), and dashed-dotted lines indicate the values used by Adams and Seinfeld (2003). Coloring indicates size range of particles. Essentially all particles in the Dentener et al. (2006) distribution are larger than $50 \mathrm{~nm}$, so these lines overlap.

\subsection{Nucleation parameterization}

The mechanisms of aerosol nucleation in the atmosphere are still very uncertain, and different schemes may predict very different nucleation rates under the same conditions. In Fig. 8, we show the effect of different nucleation parameterizations upon the modeled additional particles per $\mathrm{kg} \mathrm{SO}_{2}$ emitted for the Parish power plant. We show the additional total particles per $\mathrm{kg} \mathrm{SO}_{2}$ emitted in Fig. 8a and the additional particles larger than $30 \mathrm{~nm} \mathrm{~kg}^{-1} \mathrm{SO}_{2}$ in Fig. 8b. The classical binary nucleation scheme described by Vehkamäki et al. (2002) (Vehk, red line) does not predict any nucleation in this case because, like other classical binary nucleation schemes, it does not predict nucleation in warm lowertropospheric conditions. Therefore, there are no additional particles beyond the background concentration. There are, however, additional particles larger than $30 \mathrm{~nm}$ for the Vehk case because of condensational growth of pre-existing particles smaller than $30 \mathrm{~nm}$ that were mixed into the plume; This causes the concentration of particles larger than $30 \mathrm{~nm}$ to increase above the original background concentration; however, these are an artifact of our calculation and should not truly be considered newly-formed particles. The nucleation scheme from Merikanto et al. (2006) (Meri, cyan line) predicts too much nucleation in this case. The Meri case 

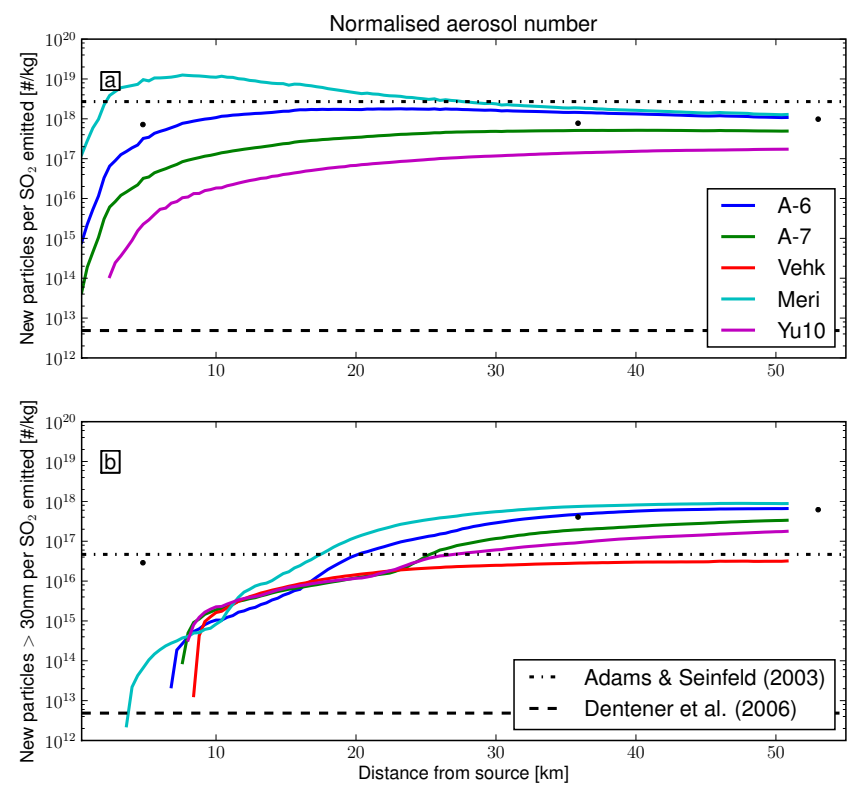

Fig. 8. (a) Total additional predicted particles and (b) additional particles larger than $30 \mathrm{~nm} \mathrm{~kg}^{-1} \mathrm{SO}_{2}$ versus distance from the Parish power-plant, using several nucleation schemes. See Sect. 3.1 for a description of the calculation. Values are averaged over the plume. Model resolution is $400 \times 400 \times 40 \mathrm{~m}$. Black dots indicate aircraft observations, solid colored lines indicate model results, black dashed lines indicate the values used by Dentener et al. (2006), and black dashed-dotted lines indicate the values used by Adams and Seinfeld (2003).

has a large number of particles close to the source that decreases away from the source due to coagulation. The nucleation rate predicted by activation-type nucleation is sensitive to the fitting parameter $A$ (Eq. 1). However, for values of $A\left(A=10^{-7} \mathrm{~s}^{-1}\right.$ : denoted by $A-7$, green line, and $A=10^{-6} \mathrm{~s}^{-1}$ : denoted by $A-6$, blue line) that typically describe nucleation in continental boundary-layer conditions (Spracklen et al., 2008; Sihto et al., 2006), the median diameter of the nucleated particles and the total number of particles agree within a factor of 2 with the observations described here, excepting the first transect. We have no measurements of the rate of ion-pair production for any of our cases, and therefore we have tested the ion-mediated nucleation scheme described by $\mathrm{Yu}(2010 \mathrm{~b})$ while prescribing 5, 10 , and 15 ion pairs $\mathrm{cm}^{-3} \mathrm{~s}^{-1}$, which we believe to be a reasonable range (Harrison and Carslaw, 2003). We found that the resultant size distribution differed, but not greatly over this range. The 10 ion pairs $\mathrm{cm}^{-1} \mathrm{~s}^{-1}$ case is shown in Fig. 8 as $\mathrm{Yu}$ (2010), the purple line. The Yu scheme somewhat under-predicts the number of new particles for the Parish case.

When excluding the Vehk case that did not predict any nucleation, the choice of nucleation scheme results in an uncertainty of about one order of magnitude in the total number particles $40 \mathrm{~km}$ downwind and onward. There is a slightly smaller uncertainty in the number of particles larger than $30 \mathrm{~nm}$ at $30 \mathrm{~km}$ downwind and onward. This highlights the importance of the nucleation scheme in predicting nucleation in the plumes. The activation nucleation scheme with an $A$-factor of $10^{-7} \mathrm{~s}^{-1}$ generally performed the best against observations for the Parish and Conesville cases and thus it was used throughout the case studies presented earlier. This shows that for these two case studies, the nucleation in the plume had a similar dependence on sulfuric acid as has been observed in both continental field observations and lab studies (Sipilä et al., 2010). However, given that the conditions are very different in the plume nucleation cases relative to regional-scale nucleation events, we stress that this similarity in sulfuric-acid dependence does not imply that the nucleation mechanisms are necessarily the same.

There is also an uncertainty of more than a factor of 3 in the fraction of produced sulfate that condenses onto the new particles rather than pre-existing particles (Table 2). However, only the Yu10 case predicted fractions within the range tested by Luo and Yu (2011). We note that the values chosen by Luo and Yu were intended to apply to all point sources of $\mathrm{SO}_{2}$ globally under all atmospheric conditions, and that the fraction of sulfate in new particles in this particular case may far exceed that of an average case for reasons independent of the nucleation mechanism (e.g. large amounts of solar radiation and moderate amounts of pre-existing aerosol).

\subsection{Background aerosol}

In order to test the sensitivity of the model to the pre-existing aerosol size distribution, we performed additional model simulations of the Parish case with background aerosol typical of a clean marine environment (MAR), and with background aerosol typical of a polluted urban environment (URB; (The original simulations are abbreviated REM for remote continental). We described the pre-existing background aerosol using three lognormal modes, with the number concentrations, median diameters, and geometric standard deviations as listed in Seinfeld and Pandis (2006), and reproduced in Table 3 of this work. The model resolution was $400 \times 400 \times 40 \mathrm{~m}$, and activation-type nucleation with an activation constant of $A=10^{-7} \mathrm{~s}^{-1}$ was used for these simulations.

The resultant additional particles per $\mathrm{kg} \mathrm{SO}_{2}$ emitted are shown in Fig. 9 ("sunny" cases, the "cloudy" cases will be described later). The MAR-sunny case has larger increases in particle number than the base case (REM-sunny) throughout the life of the plume. The low concentration of background aerosol in the MAR-sunny case implies a low condensation sink, and hence more nucleation, but nucleation-mode selfcoagulation tends to dampen this increase in number. The low background condensation sink also leads to only a small fraction of the $\mathrm{H}_{2} \mathrm{SO}_{4}$ condensing onto the existing particles, and $90 \%$ condenses onto the new particles (Table 2). The 

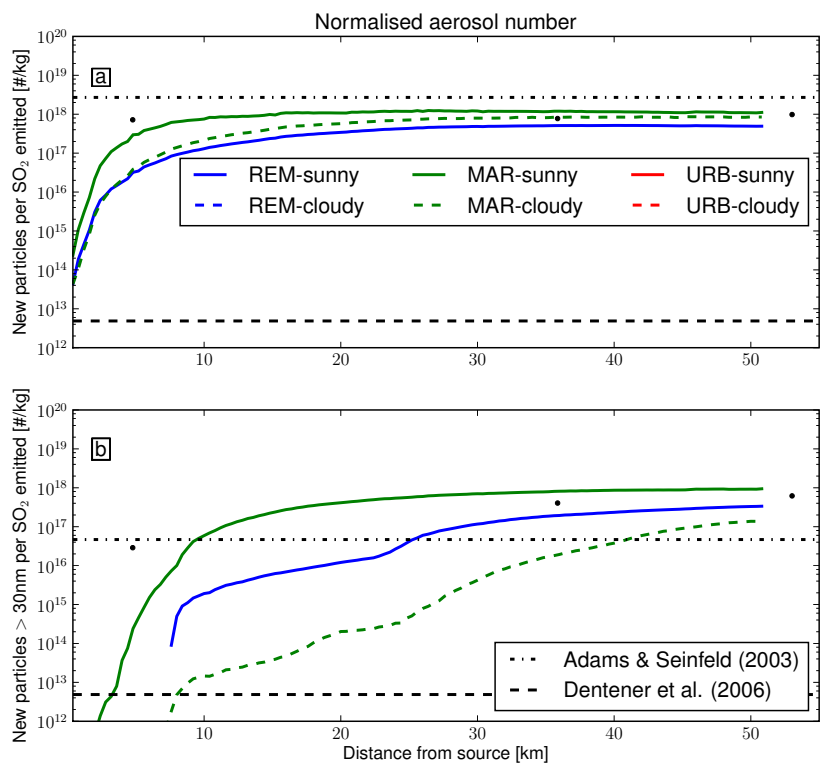

Fig. 9. (a) Total additional predicted particles and (b) additional particles larger than $30 \mathrm{~nm} \mathrm{~kg}^{-1} \mathrm{SO}_{2}$ versus distance from the Parish power-plant, for different background aerosol size distributions and differing rates of $\mathrm{OH}$ production. See Sect. 3.1 for a description of the calculation. Values are averaged over the plume. Model resolution is $400 \times 400 \times 40 \mathrm{~m}$. Black dots indicate aircraft observations, solid colored lines indicate model results, black dashed lines indicate the values used by Dentener et al. (2006), and black dashed-dotted lines indicate the values used by Adams and Seinfeld (2003). Particle numbers decreased for the REM-cloudy, URB-sunny, and URB-cloudy cases, so these lines are not visible.

newly-formed particles grow to larger sizes than in the base REM-sunny case, reaching $40 \mathrm{~nm}$ at $36 \mathrm{~km}$ from the source, at which point the particles in the base case had only reached $30 \mathrm{~nm}$.

When the model is run with an urban background (URBsunny), particle number concentrations actually decrease below their initial values, and therefore the line for the urban background case is not visible in Fig. 9. The polluted background provides a large condensation sink, and nearly all the $\mathrm{H}_{2} \mathrm{SO}_{4}$ that is formed condenses onto these particles. There is thus a low concentration of $\mathrm{H}_{2} \mathrm{SO}_{4}$ in the plume and a low nucleation rate. The large number of small particles in the urban background also yield fast coagulation rates both inside and outside of the plume. The increase in particle number due to nucleation within the plume (which is much lower than in the REM-sunny and MAR-sunny cases) is therefore less than the decrease in particle number due to coagulation.

These results show that the number of new particles formed in plumes depends greatly on the pre-existing aerosols. Next-generation parameterizations of plume subgrid particle formation must account for the amount of preexisting aerosol.

\subsection{Concentration of $\mathrm{OH}$}

As discussed in Sect. 2, we use a parameterization to predict the concentration of $\mathrm{OH}$ based on the downward shortwave radiative flux and the concentration of $\mathrm{NO}_{\mathrm{x}}$ in the model. To test the sensitivity of the model to changes in radiation, we have performed model simulations with the downward shortwave radiative flux scaled to one third of its value in the base Parish case. In these cases, we simulate the effect of cloudy overcast conditions upon $\mathrm{OH}$ production. These results are also shown in Fig. 9 (compare the "cloudy" cases to the "sunny" cases for each background aerosol concentration). $\mathrm{H}_{2} \mathrm{SO}_{4}$ production is suppressed under these cloudy conditions $\left(0.8 \%\right.$ of the $\mathrm{SO}_{2}$ has oxidized at $50 \mathrm{~km}$ compared to $9 \%$ for the sunny cases; Table 2), and therefore new-particle formation and growth is also suppressed. Regardless of the aerosol background, there are fewer particles formed within the plume. For the base case remote-continental aerosol background (REM-cloudy), very little nucleation occurs under these cloudy conditions, and the nucleated particles do not grow beyond $6 \mathrm{~nm}$. Like the URB-sunny case described above, more particles are lost to coagulation than are formed by nucleation, and thus the line for the REM-cloudy case is not visible in Fig. 9. The URB-cloudy case is also not visible for the same reason. Under clean marine aerosol background conditions (MAR-cloudy), similar numbers of particles form, but the particles grow more slowly and do not reach the same size as in the MAR-sunny case. In the MARcloudy case the particles grow beyond $30 \mathrm{~nm}$ in diameter further downwind of the plume's source and a smaller fraction of the particles grow larger than $30 \mathrm{~nm}$ in diameter. These results show that we would expect very little particle formation and growth at night in the plumes except for cases where $\mathrm{SO}_{3}$ is emitted from the plant (e.g. Zaveri et al., 2010).

We do not yet explicitly account for the effect of VOCs upon $\mathrm{OH}$ concentrations within the model. In order to determine the sensitivity of our results to this uncertainty, we ran our model under low-VOC conditions (as described in Sect. 2). The concentrations of trace gases and particle number concentrations are shown in Fig. 10. For a constant shortwave radiation flux, maximum steady-state concentrations of $\mathrm{OH}$ occur at a $\mathrm{NO}_{\mathrm{x}}$ concentration that depends on the concentrations of VOCs. Under high-VOC conditions, this $\mathrm{NO}_{\mathrm{x}}$ concentration that yields the maximum concentration of $\mathrm{OH}$ will be larger than under low-VOC conditions. The parameterization we use to estimate concentrations of $\mathrm{OH}$ yields a maximum concentration of $\mathrm{OH}$ for $\mathrm{NO}_{\mathrm{x}}$ mixing ratios of $1.2 \mathrm{ppbv}$ under low-VOC conditions, and $2.0 \mathrm{ppbv}$ under high-VOC conditions. Since the area inside the plume has very high mixing ratios of $\mathrm{NO}_{\mathrm{x}}$, larger than $5 \mathrm{ppbv}$ in the Parish case (even far from the source), the mixing ratios of $\mathrm{NO}_{\mathrm{x}}$ will be closer to those that yield the maximum possible concentrations of $\mathrm{OH}$ under high-VOC conditions than under low-VOC conditions (all other parameters are held constant). Because of these high $\mathrm{NO}_{\mathrm{x}}$ mixing ratios, more $\mathrm{H}_{2} \mathrm{SO}_{4}$ is 
Table 3. Background aerosol size distributions used for sensitivity studies. From Seinfeld and Pandis (2006).

\begin{tabular}{lrrr|rrr}
\hline & \multicolumn{3}{c}{ Marine } & \multicolumn{3}{c}{ Urban } \\
& Mode 1 & Mode 2 & Mode 3 & Mode 1 & Mode 2 & Mode 3 \\
\hline Number concentration $\left[\mathrm{cm}^{-3}\right]$ & 133 & 66.6 & 3.1 & $9.93 \times 10^{4}$ & $1.11 \times 10^{3}$ & $3.64 \times 10^{4}$ \\
Median diameter $[\mu \mathrm{m}]$ & 0.01 & 0.27 & 0.58 & 0.01 & 0.01 & 0.05 \\
Geometric standard deviation & 4.54 & 1.62 & 2.49 & 1.76 & 4.63 & 2.17 \\
\hline
\end{tabular}

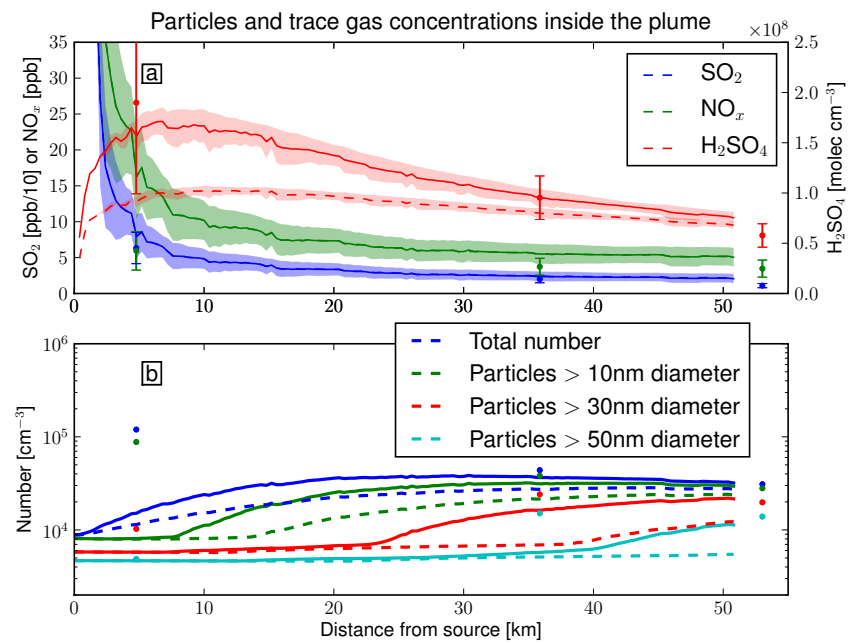

Fig. 10. (a) Trace gases and (b) particle number vs. distance downwind from the Parish power plant averaged over the plume for differing rates of $\mathrm{OH}$ production due to different assumptions of VOC concentrations. Dots are aircraft observations; lines are model results. Shaded area and error bars indicate one standard deviation in concentration across plume width. The results of the high-VOC case are shown as a solid line, and the results of the low- VOC case are shown as a dashed line. Model resolution is $400 \times 400 \times 40 \mathrm{~m}$.

produced under the high-VOC conditions than under the lowVOC conditions. Under the high-VOC conditions, $9 \%$ of the $\mathrm{SO}_{2}$ has oxidized at $50 \mathrm{~km}$ from the source, while $6 \%$ of the $\mathrm{SO}_{2}$ oxidized under low-VOC conditions (Table 2). Note that the predicted concentration of $\mathrm{NO}_{\mathrm{x}}$ is unchanged between cases and $\mathrm{SO}_{2}$ is only slightly changed. The higher concentrations of $\mathrm{H}_{2} \mathrm{SO}_{4}$ in the high-VOC case result in more nucleation and growth, and thus higher concentrations of aerosols at all sizes. In the low-VOC case, few particles grow to diameters larger than $30 \mathrm{~nm}$ within $50 \mathrm{~km}$ of the source, and almost no particles grow beyond $50 \mathrm{~nm}$.

Although these effects of VOCs on the size distribution are not as strong as the effects of changes in the background aerosol concentrations or switching between sunny and cloudy conditions as shown above, they too are important for predicting the formation and growth of particles in plumes. An additional potentially important effect of atmospheric organics that was not tested here is the effect of secondary organic aerosol (SOA) formation in the plumes. Condensing SOA will help grow the ultrafine mode to $\mathrm{CCN}$ relevant sizes (Riipinen et al., 2011 and Pierce et al., 2011). The lack of SOA in our model may be part of the reason that our model predictions of the concentration of particles larger than $50 \mathrm{~nm}$ were biased low compared with the observations. Early in the plume, $\mathrm{H}_{2} \mathrm{SO}_{4}$ formation should dominate condensational growth; however, as the plume is diluted with background air, SOA may dominate the growth of particles in some cases. Thus, it will be important in future work to explore the effect of SOA in power-plant plume microphysics.

\section{Conclusions}

We have implemented online aerosol microphysics into an LES/CRM model. We have shown, through two case studies, that the model provides reasonable predictions of newparticle formation and growth within the plume at distances further than $10-20 \mathrm{~km}$ from the source. For both cases, we predicted about one order of magnitude fewer total particles produced for each $\mathrm{kg} \mathrm{SO}_{2}$ emitted than the assumptions used by Adams and Seinfeld (2003) and related studies, but several orders of magnitude more particles per $\mathrm{kg} \mathrm{SO}_{2}$ than indicated in Dentener et al. (2006). This result was robust across all of the nucleation parameterizations we tested (except for classical binary nucleation, which predicted no new-particle formation in these warm conditions).

We have run the model using two horizontal resolutions, $400 \mathrm{~m} \times 400 \mathrm{~m}$ and $800 \mathrm{~m} \times 800 \mathrm{~m}$. The discrepancy in the number of particles predicted was less than a factor of 1.5 . This was less than the uncertainty in the number of particles produced due to uncertainties in VOCs or different nucleation parameterizations. We therefore expect that using a model resolution finer than $800 \mathrm{~m} \times 800 \mathrm{~m}$ horizontal resolution would not enhance the accuracy of the model predictions at this time.

The two case studies shown here are certainly not representative of all cases, and we have included a small number of sensitivity studies to show how our results would differ under alternative aerosol background conditions and lower $\mathrm{OH}$ production rates. We find that for polluted background conditions, new-particle formation can be negligible. With a clean marine background, total particle numbers are about 
a factor of 2 larger than the remote-continental base case, and the newly-formed particles grow to larger sizes. If we reduce the production rate of $\mathrm{OH}$, as it would be reduced under cloudy overcast conditions, we see less new-particle formation and slower growth of all particles. In the simulated cloudy conditions, nucleation was negligible in both the moderately polluted remote continental background case and the very polluted urban background case.

We found that $9 \%$ and $4 \%$ of the emitted $\mathrm{SO}_{2}$ oxidized to form $\mathrm{H}_{2} \mathrm{SO}_{4}$ within $50 \mathrm{~km}$ of the source in the Parish and Conesville cases, respectively. If the production rate of $\mathrm{OH}$ is decreased in the Parish case according to cloudy or lowVOC conditions, the fraction of $\mathrm{SO}_{2}$ oxidized decreases from $9 \%$ to $0.8 \%$ or $6 \%$, respectively. The base Parish case and the low-VOC Parish case values are larger than those chosen in many studies (Adams and Seinfeld, 2003; Spracklen et al., 2005; Wang and Penner, 2009; Luo and Yu, 2011). However, this is implicitly accounted for to some degree by the oxidation of the emitted $\mathrm{SO}_{2}$ in subsequent time steps in these models, and the cases here were for daytime conditions which would have above-average oxidation rates.

The work in this paper highlights how new-particle formation and growth in power-plant plumes (and anthropogenic sulfur plumes in general) depend greatly on meteorological conditions and the pre-existing particle concentrations. A power plant with constant emissions may have efficient nucleation and growth in its plume on one day, but negligible nucleation and growth on another. These results show the need for a new generation of schemes for accounting for particle formation in sub-grid sulfur plumes. Other factors that were not tested here that may be important in the plume microphysics are $\mathrm{SO}_{2}$ and $\mathrm{NO}_{\mathrm{x}}$ emissions rates, primary particle emissions (either as ash or $\mathrm{H}_{2} \mathrm{SO}_{4}$ formed in the plant/stack), SOA formation in the plume, wind speeds and atmospheric stability. These should also be addressed in future work.

Using the model described here, it is our intent to develop a computationally efficient, but physically based, coal-fired power plant emissions parameterization that depends on the emissions from the stack, the mean meteorological conditions and the mean background aerosol and gas concentrations that can be resolved by regional and global models. This parameterization will allow for more accurate predictions of aerosol size distributions and a greater confidence in the effects of aerosols in climate and health studies.

Until this parameterization is available, it may be wise to consider separately conditions under which it is likely there will rarely be significant aerosol nucleation within the plume. Based on our sensitivity studies, when $\mathrm{OH}$ concentrations are very low (for instance, at night) or when the background condensation sink is very high, it seems prudent to assume that all $\mathrm{H}_{2} \mathrm{SO}_{4}$ formed within the plume will condense onto the existing background aerosol, and that therefore aerosol mass should be increased without increasing number. Under other conditions, it may be preferable to assume the size distribu- tion used by Adams and Seinfeld (2003) to the size distribution assumed by Dentener et al. (2006), as the former was closer to the results we obtained for every case where particle number concentration increased inside the plume. We wish to stress that this does not imply that it will be the better assumption under all conditions, but our results suggest that it may be the better assumption under conditions when nucleation does occur.

\section{Appendix A}

\section{OH Parameterization Details}

As mentioned in Sect. 2, the $\mathrm{OH}$ parameterization used in the SAM-TOMAS model is an empirical fit to the results of many simulations from the detailed time-dependent photochemical box model described by Olson et al. (2006). These simulations span conditions observed below $1 \mathrm{~km}$ over the eastern United States as sampled from the NASA DC-8 during the Intercontinental Chemical Transport ExperimentNorth America (INTEX-A) field campaign (Singh et al., 2006). The $\mathrm{OH}$ parameterization fits the detailed model calculations well for all simulations except those with high levels of isoprene. Thus, the initial parameterization was derived based on calculations for conditions where the observed isoprene mixing ratio was $150 \mathrm{pptv}$ or less. This base $\mathrm{OH}$ parameterization is referred to as the "low-VOC" case. The $\mathrm{OH}$ parameterization works as follows. First, we set variables $x$ and $y$ :

$x=\log \left(\left[\mathrm{NO}_{\mathrm{x}}\right]\right)-0.195$

$y=\frac{\mathrm{dswrf}}{S_{0} \cdot T}$

where $\left[\mathrm{NO}_{\mathrm{x}}\right]$ is the mixing ratio of $\mathrm{NO}_{\mathrm{x}}$ in ppbv, dswrf is the downward shortwave radiative flux at the surface in $\mathrm{W} \mathrm{m}^{-2}, S_{0}$ is the solar constant at the top of the atmosphere, $1370 \mathrm{~W} \mathrm{~m}^{-2}$, and $T$ is an assumed transmittance of the clear atmosphere, 0.76 . The first polynomial $(P 1)$ estimates the shape of the $\mathrm{OH}$ versus $\mathrm{NO}_{\mathrm{x}}$ relationship:

$P 1=-0.014 x^{6}+0.0027 x^{5}+0.1713 x^{4}-0.0466 x^{3}$

$-0.7893 x^{2}-0.1739 x+6.9414$

The second polynomial scales the curve based on dswrf:

$P 2=\left(-1345 y^{3}+4002 y^{2}-471.8 y+42.72\right) \times 10^{4}$

Finally, we calculate the concentration of $\mathrm{OH}$ in molecules $\mathrm{cm}^{-3}$ :

$[\mathrm{OH}]=0.82 \cdot 10^{P 1 \times \log (P 2) / 6.8}$ 
One process not accounted for in the $\mathrm{OH}$ parameterization is the effect of the presence of large amounts of highly reactive VOCs on $\mathrm{OH}$ production. This was revealed by the difficulty in devising a parameterization that could encompass the $\mathrm{OH}$ calculations associated with high isoprene mixing ratios during INTEX-A. The additional peroxy radicals from isoprene oxidation induce a shift in the peak $\mathrm{OH}$ production to a higher $\mathrm{NO}_{\mathrm{x}}$ level. To understand the potential effect of high VOC concentrations in our study, a second parameterization, referred to as the "high-VOC" case, was developed based on an isoprene mixing ratio of $1.5 \mathrm{ppbv}$ (the 95th percentile value observed during INTEX-A). This parameterization uses the the following equation for $x$ (all other equations the same):

$x=\log \left(\left[\mathrm{NO}_{\mathrm{x}}\right] \times 0.6\right)-0.195$

In this way, we shift the concentration of $\mathrm{NO}_{\mathrm{x}}$ that corresponds to the peak concentration of $\mathrm{OH}$ from $\sim 1.2 \mathrm{ppbv}$ in the low-VOC case to $\sim 2.0 \mathrm{ppbv}$ in the high-VOC case. Due to the proximity of our test cases to known biogenic and anthropogenic sources of VOCs, we assume high-VOC conditions for purposes of calculating $\mathrm{OH}$ in all the model runs described below, except where explicitly stated otherwise. In the Parish case, the plume passes over major roadways and urban sprawl surrounding Houston; In the Conesville case, the plume passes over a heavily forested region during late summer when biogenic emissions would be high. We perform sensitivity simulations to test this high-VOC assumption.

As a final note regarding the calculation of $\mathrm{OH}$, it is important to point out that field observations suggest that current chemical mechanisms tend to underestimate $\mathrm{OH}$ levels in environments of high $\mathrm{NO}_{\mathrm{x}}$ (Shen et al., 2009 and references therein) and high isoprene (Lelieveld et al., 2008; Hofzumahaus et al., 2009; Stone et al., 2011). While adequate chemical mechanisms to represent these field observations do not exist, it is reasonable to expect that true peak $\mathrm{OH}$ concentrations are shifted to higher $\mathrm{NO}_{\mathrm{x}}$ than these calculations would suggest.

Acknowledgements. This research was funded by the Electric Power Research Institute (EPRI). We would like to thank Marat Khairoutdinov of the School of Marine and Atmospheric Sciences, Stony Brook University, for access to and help with the System for Atmospheric Modeling. NCEP Reanalysis data provided by the NOAA/OAR/ESRL PSD, Boulder, Colorado, USA, from their Web site at http://www.esrl.noaa.gov/psd/.

Edited by: V.-M. Kerminen

\section{References}

Adams, P. J. and Seinfeld, J. H.: Predicting global aerosol size distributions in general circulation models, J. Geophys. Res., 107, 4370, doi:10.1029/2001JD001010, 2002.
Adams, P. J. and Seinfeld, J. H.: Disproportionate impact of particulate emissions on global cloud condensation nuclei concentrations, Geophys. Res. Lett., 30, 1239 , doi:10.1029/2002GL016303, 2003.

Albrecht, B.: Aerosols, Cloud Microphysics, and Fractional Cloudiness, Science, 245, 1227-1230, 1989.

Brock, C. A., Washenfelder, R. A., Trainer, M., Ryerson, T. B., Wilson, J. C., Reeves, J. M., Huey, L. G., Holloway, J. S., Parrish, D. D., Hübler, G., and Fehsenfeld, F. C.: Particle growth in the plumes of coal-fired power plants, J. Geophys. Res., 107, 4155, doi:10.1029/2001JD001062, 2002.

Brown, S. S., Dube, W. P., Osthoff, H. D., Stutz, J., Ryerson, T. B., Wollny, A. G., Brock, C. A., Warneke, C., De Gouw, J. A., Atlas, E., Neuman, J. A., Holloway, J. S., Lerner, B. M., Williams, E. J., Kuster, W. C., Goldan, P. D., Angevine, W. M., Trainer, M., Fehsenfeld, F. C., and Ravishankara, A. R.: Vertical profiles in $\mathrm{NO}_{3}$ and $\mathrm{N}_{2} \mathrm{O}_{5}$ measured from an aircraft: Results from the NOAA P-3 and surface platforms during the new england air quality study 2004, J. Geophys. Res.-Atmos., 112, D22304, doi:10.1029/2007JD008883, 2007.

Charlson, R. J., Schwartz, S. E., Hales, J. M., Cess, R. D., Coakley, J. A., Hansen, J. E., and Hofmann, D. J.: Climate Forcing by Anthropogenic Aerosols, Science, 255, 423-430, 1992.

Cichanowicz, J. E.: Estimating total sulfuric acid emissions from stationary power plants, Rep. 1016384, Electr. Power Res. Inst., Palo Alto, Calif, 2008.

Clean Air Markets - Data and Maps: http://camddataandmaps.epa. gov/gdm/, last access: December 2010.

Dentener, F., Kinne, S., Bond, T., Boucher, O., Cofala, J., Generoso, S., Ginoux, P., Gong, S., Hoelzemann, J. J., Ito, A., Marelli, L., Penner, J. E., Putaud, J.-P., Textor, C., Schulz, M., van der Werf, G. R., and Wilson, J.: Emissions of primary aerosol and precursor gases in the years 2000 and 1750 prescribed data-sets for AeroCom, Atmos. Chem. Phys., 6, 4321-4344, doi:10.5194/acp6-4321-2006, 2006.

Dockery, D. W., Pope, C. A., Xu, X. P., Spengler, J. D., Ware, J. H., Fay, M. E., Ferris, B. G., and Speizer, F. E.: An association between air-pollution and mortality in 6 United-States cities, New Engl. J. Med., 329, 1753-1759, 1993.

Fanaki, F. H.: Experimental observations of a bifurcated buoyant plume, Bound.-Layer Meteorol., 9, 479-495, 1975.

Fountoukis, C., Nenes, A., Meskhidze, N., Bahreini, R., Conant, W. C., Jonsson, H., Murphy, S., Sorooshian, A., Varutbangkul, V., Brechtel, F., Flagan, R. C., and Seinfeld, J. H.: Aerosol-cloud drop concentration closure for clouds sampled during the International Consortium for Atmospheric Research on Transport and Transformation 2004 campaign, J. Geophys. Res., 112, D10S30, doi:10.1029/2006JD007272, 2007.

Harrison, R. G. and Carslaw, K. S.: Ion-aerosol-cloud processes in the lower atmosphere, Rev. Geophys., 41, 1012, doi:10.1029/2002RG000114, 2003.

Hegg, D. A. and Hobbs, P. V.: Measurements of gas-to-particle conversion in the plumes from 5 coal-fired electric-power plants, Atmos. Environ., 14, 99-116, 1980.

Hegg, D. A., Hobbs, P. V., and Lyons, J. H.: Field studies of a power-plant plume in the arid southwestern united-states, Atmos. Environ., 19, 1147-1167, 1985.

Hofzumahaus, A., Rohrer, F., Lu, K., Bohn, B., Brauers, T., Chang, C. C., Fuchs, H., Holland, F., Kita, K., Kondo, Y., Li, X., Lou, S., 
Shao, M., Zeng, L., Wahner, A., and Zhang, Y.: Amplified trace gas removal in the troposphere, Science, 324, 1702-1704, 2009.

Kerminen, V-M. and Wexler, A. S.: The Interdependence of Aerosol Processes and Mixing in Point Source Plumes, Atmos. Environ. 29, 361-375, 1995.

Kerminen, V.-M. and Kulmala, M.: Analytical formulae connecting the "real" and the "apparent" nucleation rate and the nuclei number concentration for atmospheric nucleation events, J. Aerosol Sci., 33, 609-622, 2002.

Khairoutdinov, M. F. and Randall, D. A.: Cloud Resolving Modeling of the ARM Summer 1997 IOP: Model Formulation, Results, Uncertainties, and Sensitivities, J. Atmos. Sci., 60, 607625, 2003.

Kleffmann, J.: Daytime sources of nitrous acid (HONO) in the atmospheric boundary layer, ChemPhysChem, 8, 1137-1144, doi:10.1002/cphc.200700016, 2007.

Kulmala, M. and Kerminen, V.: On the formation and growth of atmospheric nanoparticles, Atmos. Res., 90, 132-150, doi:10.1016/j.atmosres.2008.01.005, 2008.

Kulmala, M., Lehtinen, K. E. J., and Laaksonen, A.: Cluster activation theory as an explanation of the linear dependence between formation rate of $3 \mathrm{~nm}$ particles and sulphuric acid concentration, Atmos. Chem. Phys., 6, 787-793, doi:10.5194/acp-6-787-2006, 2006.

Lelieveld, J., Butler, T. M., Crowley, J. N., Dillon, T. J., Fischer, H., Ganzeveld, L., Harder, H., Lawrence, M. G., Martinez, M., Taraborrelli, D., and Williams, J.: Atmospheric oxidation capacity sustained by a tropical forest, Nature, 452, 737-740, 2008.

Li, G., Lei, W., Zavala, M., Volkamer, R., Dusanter, S., Stevens, P., and Molina, L. T.: Impacts of HONO sources on the photochemistry in Mexico City during the MCMA-2006/MILAGO Campaign, Atmos. Chem. Phys., 10, 6551-6567, doi:10.5194/acp10-6551-2010, 2010.

Luo, G. and Yu, F.: Sensitivity of global cloud condensation nuclei concentrations to primary sulfate emission parameterizations, Atmos. Chem. Phys., 11, 1949-1959, doi:10.5194/acp-111949-2011, 2011.

Makkonen, R., Asmi, A., Korhonen, H., Kokkola, H., JÄrvenoja, S., Räisänen, P., Lehtinen, K. E. J., Laaksonen, A., Kerminen, V.-M., Järvinen, H., Lohmann, U., Bennartz, R., Feichter, J., and Kulmala, M.: Sensitivity of aerosol concentrations and cloud properties to nucleation and secondary organic distribution in ECHAM5-HAM global circulation model, Atmos. Chem. Phys., 9, 1747-1766, doi:10.5194/acp-9-1747-2009, 2009.

Merikanto, J., Napari, I., Vehkamäki, H., Anttila, T., and Kulmala, M.: New parameterization of sulfuric acid-ammonia-water ternary nucleation rates at tropospheric conditions, J. Geophys. Res., 112, D15207, doi:10.1029/2006JD007977, 2006.

Mesinger, F., Dimego, G., Kalnay, E., Mitchell, K., Shafran, P. C., Ebisuzaki, W., Joviæ, D., Woollen, J., Rogers, E., Berbery, E. H., Ek, M. B., Fan, Y., Grumbine, R., Higgins, W., Li, H., Lin, Y., Manikin, G., Parrish, D., and Shi, W.: North American Regional Reanalysis: A long-term, consistent, high-resolution climate dataset for the North American domain, as a major improvement upon the earlier global reanalysis datasets in both resolution and accuracy, B. Am. Meteorol. Soc., 87, 343-360, 2006.

Mueller, S. F. and Imhoff, R. E.: Estimates of particle formation and growth in coal-fired boiler exhaust Part 1: Observations, Atmos. Environ., 28, 595-602, 1994.
Napari, I., Noppel, M., Vehkamäki, H., and Kulmala M.: Parametrization of Ternary Nucleation Rates for $\mathrm{H}_{2} \mathrm{SO}_{4}$ $\mathrm{NH}_{3}-\mathrm{H}_{2} \mathrm{O}$ Vapors, J. Geophys. Res.-Atmos. 107, 4381, doi:10.1029/2002JD002132, 2002.

Olaguer, E. P., Rappenglück, B., Lefer, B., Stutz, J., Dibb, J., Griffin, R., Brune, W. H., Shauck, M., Buhr, M., Jeffries, H., Vizuete, W., and Pinto, J. P.: Deciphering the role of radical precursors during the Second Texas Air Quality Study, J. Air Waste Ma., 59, 1258-1277, 2009.

Olson, J. R., Crawford, J. H., Chen, G., Brune, W. H., Faloona, I. C., Tan, D., Harder, H., and Martinez, M.: A reevaluation of airborne $\mathrm{HO}_{\mathrm{x}}$ observations from NASA field campaigns, J. Geophys. Res., 111, D10301, doi:10.1029/2005JD006617, 2006.

Parrish, D. D., Allen, D. T., Bates, T. S., Estes, M., Fehsenfeld, F. C., Feingold, G., Ferrare, R., Hardesty, R. M., Meagher, J. F., Nielsen-Gammon, J. W., Pierce, R. B., Ryerson, T. B., Seinfeld, J. H. and Williams, E. J.: Overview of the Second Texas Air Quality Study (TexAQS II) and the Gulf of Mexico Atmospheric Composition and Climate Study (GoMACCS), J. Geophys. Res., 114, D00F13, doi:10.1029/2009JD011842, 2009.

Peters, A., Wichmann, H. E., Tuch, T., Heinrich, J., and Heyder, J.: Respiratory effects are associated with the number of ultrafine particles, Am. J. Resp. Crit. Care, 155, 1376-1383, 1997.

Pierce, J. R. and Adams, P. J.: Global evaluation of CCN formation by direct emission of sea salt and growth of ultrafine sea salt, J. Geophys. Res.-Atmos., 111, D06203, doi:10.1029/2005JD006186, 2006.

Pierce, J. R. and Adams, P. J.: Uncertainty in global CCN concentrations from uncertain aerosol nucleation and primary emission rates, Atmos. Chem. Phys., 9, 1339-1356, doi:10.5194/acp-91339-2009, 2009.

Pierce, J. R., Chen, K., and Adams, P. J.: Contribution of primary carbonaceous aerosol to cloud condensation nuclei: processes and uncertainties evaluated with a global aerosol microphysics model, Atmos. Chem. Phys., 7, 5447-5466, doi:10.5194/acp-75447-2007, 2007.

Pierce, J. R., Riipinen, I., Kulmala, M., Ehn, M., Petäjä, T., Junninen, H., Worsnop, D. R., and Donahue, N. M.: Quantification of the volatility of secondary organic compounds in ultrafine particles during nucleation events, Atmos. Chem. Phys., 11, 90199036, doi:10.5194/acp-11-9019-2011, 2011.

Riipinen, I., Pierce, J. R., Yli-Juuti, T., Nieminen, T., Häkkinen, S., Ehn, M., Junninen, H., Lehtipalo, K., Petäjä, T., Slowik, J., Chang, R., Shantz, N. C., Abbatt, J., Leaitch, W. R., Kerminen, V.-M., Worsnop, D. R., Pandis, S. N., Donahue, N. M., and Kulmala, M.: Organic condensation: a vital link connecting aerosol formation to cloud condensation nuclei (CCN) concentrations, Atmos. Chem. Phys., 11, 3865-3878, doi:10.5194/acp-11-38652011, 2011.

Sihto, S.-L., Kulmala, M., Kerminen, V.-M., Dal Maso, M., Petäjä, T., Riipinen, I., Korhonen, H., Arnold, F., Janson, R., Boy, M., Laaksonen, A., and Lehtinen, K. E. J.: Atmospheric sulphuric acid and aerosol formation: implications from atmospheric measurements for nucleation and early growth mechanisms, Atmos. Chem. Phys., 6, 4079-4091, doi:10.5194/acp-6-4079-2006, 2006.

Singh, H. B., Brune, W. H., Crawford, J. H., Jacob, D. J., and Russell, P. B.: Overview of the summer 2004 Intercontinental Chemical Transport Experiment-North America (INTEX-A), J. Geo- 
phys. Res., 111, D24S01, doi:10.1029/2006JD007905, 2006.

Sipilä, M., Berndt, T., Petäjä, T., Brus, D., Vanhanen, J., Stratmann, F., Patokoski, J., Mauldin, Roy L. III, Hyvärinen, A., Lihavainen, H., and Kulmala, M.: The role of sulfuric acid in atmospheric nucleation, Science, 327, 1243-1246, doi:10.1126/science.1180315, 2010.

Solomon, S., Qin, D., Manning, M., Chen, Z., Marquis, M., Averyt, K. B., Tignor, M., and Miller, H. L.: Climate change 2007: The Physical Science Basis, Contribution of Working Group 1 to the Fourth Assessment Report of the Intergovernmental Panel on Climate Change, IPCC, Cambridge University Press, Cambridge, UK, and New York, USA, 2007.

Srivastava, R. K., Miller, C. A., Erickson C., and Jambhekar, R.: Emissions of sulfur trioxide from coal-fired power plants, J. Air Waste Ma., 54, 750-762, 2004.

Seinfeld, J. H. and Pandis, S. N.: Atmospheric Chemistry and Physics: From Air Pollution to Climate Change, Part 2, John Wiley and Sons, Inc., Hoboken, New Jersey, 2006.

Spracklen, D. V., Pringle, K. J., Carslaw, K. S., Chipperfield, M. P., and Mann, G. W.: A global off-line model of size-resolved aerosol microphysics: II. Identification of key uncertainties, Atmos. Chem. Phys., 5, 3233-3250, doi:10.5194/acp-5-3233-2005, 2005.

Spracklen, D. V., Carslaw, K. S., Kulmala, M., Kerminen, V., Sihto, S., Riipinen, I., Merikanto, J., Mann, G. W., Chipperfield, M. P., Wiedensohler, A., Birmili, W., and Lihavainen, H.: Contribution of particle formation to global cloud condensation nuclei concentrations, Geophys. Res. Lett., 35, L06808, doi:10.1029/2007GL033038, 2008.

Slinn, W. G. N., Hasse, L., Hicks, B. B., Hogan, A. W., Lai, D., Liss, P. S., Munnich, K. O., Sehmel, G. A., and Vittori, O.: Some aspects of the transfer of atmospheric trace constituents past the air-sea interface, Atmos. Environ. 12, 2055-2087, 1978.

Stone, D., Evans, M. J., Edwards, P. M., Commane, R., Ingham, T., Rickard, A. R., Brookes, D. M., Hopkins, J., Leigh, R. J., Lewis, A. C., Monks, P. S., Oram, D., Reeves, C. E., Stewart, D., and Heard, D. E.: Isoprene oxidation mechanisms: measurements and modelling of $\mathrm{OH}$ and $\mathrm{HO}_{2}$ over a South-East Asian tropical rainforest during the $\mathrm{OP}_{3}$ field campaign, Atmos. Chem. Phys., 11, 6749-6771, doi:10.5194/acp-11-6749-2011, 2011.
Twomey, S.: Pollution and planetary albedo, Atmos. Environ., 8, 1251-1256, 1974

Vehkamäki, H., Kulmala, M., Napari, I., Lehtinen, K. E. J., Timmreck, C., Noppel, M., and Laaksonen. A.: An Improved Parameterization for Sulfuric Acid-Water Nucleation Rates for Tropospheric and Stratospheric Conditions, J. Geophys. Res.-Atmos., 107, 4622, doi:10.1029/2002JD002184, 2002.

Volkamer, R., Sheehy, P., Molina, L. T., and Molina, M. J.: Oxidative capacity of the Mexico City atmosphere - Part 1: A radical source perspective, Atmos. Chem. Phys., 10, 6969-6991, doi:10.5194/acp-10-6969-2010, 2010.

Wang, M. and Penner, J. E.: Aerosol indirect forcing in a global model with particle nucleation, Atmos. Chem. Phys., 9, 239-260, doi:10.5194/acp-9-239-2009, 2009.

Westervelt, D. M., Riipinen, I., Pierce, J. R., Trivitayanurak, W., and Adams, P. J.: Formation and Growth of Nucleated Particles into Cloud Condensation Nuclei: Comparison of a Global Aerosol Model with Observations, in preparation for Atmos. Chem. Phys. Diss., 2011.

Whitby, K. T.: Physical characteristics of sulfur aerosols, Atmos. Environ., 12, 135-159, 1978.

Yu, F. and Luo, G.: Simulation of particle size distribution with a global aerosol model: contribution of nucleation to aerosol and CCN number concentrations, Atmos. Chem. Phys., 9, 76917710, doi:10.5194/acp-9-7691-2009, 2009.

Yu, F.: Diurnal and Seasonal Variations of Ultrafine Particle Formation in Anthropogenic $\mathrm{SO}_{2}$ Plumes, Environ. Sci. Technol., 44, 2011-2015, 2010a.

Yu, F.: Ion-mediated nucleation in the atmosphere: Key controlling parameters, implications, and look-up table, J. Geophys. Res., 115, D03206, doi:10.1029/2009JD012630, 2010b.

Zaveri, R. A., Berkowitz, C. M., Brechtel, F. J., Gilles, M. K., Hubbe, J. M., Jayne, J. T., Kleinman, L. I., Laskin, A., Madronich, S., Onasch, T. B., Pekour, M. S., Springston, S. R., Thornton, J. A., Tivanski, A. V., and Worsnop, D. R.: Nighttime chemical evolution of aerosol and trace gases in a power plant plume: Implications for secondary organic nitrate and organosulfate aerosol formation, $\mathrm{NO}_{3}$ radical chemistry, and $\mathrm{N}_{2} \mathrm{O}_{5}$ heterogeneous hydrolysis, J. Geophys. Res.-Atmos., 115, D12304, doi:10.1029/2009JD013250, 2010. 